\title{
Developmental deficits and staging
} of dynamics of age associated Alzheimer's disease neurodegeneration and neuronal loss in subjects with Down syndrome

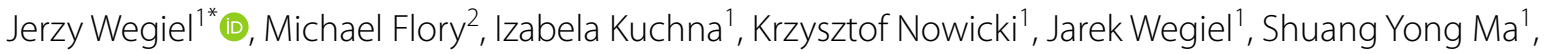
Nanbert Zhong ${ }^{2}$, Teresa Wierzba Bobrowicz ${ }^{3}$, Mony de Leon ${ }^{4}$, Florence Lai ${ }^{5}$, Wayne P. Silverman ${ }^{6}$ and Thomas Wisniewski ${ }^{7}$

\begin{abstract}
The increased life expectancy of individuals with Down syndrome (DS) is associated with increased prevalence of trisomy 21-linked early-onset Alzheimer's disease (EOAD) and dementia. The aims of this study of 14 brain regions including the entorhinal cortex, hippocampus, basal ganglia, and cerebellum in 33 adults with DS 26-72 years of age were to identify the magnitude of brain region-specific developmental neuronal deficits contributing to intellectual deficits, to apply this baseline to identification of the topography and magnitude of neurodegeneration and neuronal and volume losses caused by EOAD, and to establish age-based staging of the pattern of genetically driven neuropathology in DS. Both DS subject age and stage of dementia, themselves very strongly correlated, were strong predictors of an AD-associated decrease of the number of neurons, considered a major contributor to dementia. The DS cohort was subclassified by age as pre-AD stage, with 26-41-year-old subjects with a full spectrum of developmental deficit but with very limited incipient AD pathology, and 43-49, 51-59, and 61-72-year-old groups with predominant prevalence of mild, moderately severe, and severe dementia respectively. This multiregional study revealed a $28.1 \%$ developmental neuronal deficit in DS subjects 26-41 years of age and 11.9\% AD-associated neuronal loss in DS subjects 43-49 years of age; a 28.0\% maximum neuronal loss at 51-59 years of age; and a 11.0\% minimum neuronal loss at 61-72 years of age. A total developmental neuronal deficit of 40.8 million neurons and AD-associated neuronal loss of 41.6 million neurons reflect a comparable magnitude of developmental neuronal deficit contributing to intellectual deficits, and AD-associated neuronal loss contributing to dementia. This highly predictable pattern of pathology indicates that successful treatment of DS subjects in the fourth decade of life may prevent AD pathology and functional decline.
\end{abstract}

Keywords: Down syndrome, Alzheimer's disease, Clinicopathological staging, Developmental neuronal deficits, Neuronal loss, Neurofibrillary degeneration, $\beta$-amyloidosis, Lewy bodies, TDP-43 neurodegeneration, Stereology

\footnotetext{
*Correspondence: Jerzy.Wegiel@opwdd.ny.gov

${ }^{1}$ Department of Developmental Neurobiology, NYS Institute for Basic

Research in Developmental Disabilities, 1050 Forest Hill Road, Staten Island, NY 10314, USA

Full list of author information is available at the end of the article
}

\section{Introduction}

Down syndrome (DS), caused by trisomy of chromosome 21 [31, 42], is the most common form of chromosomal abnormality; its prevalence increased between 1979 and 2003 from 9.0 to 11.8 per 10,000 live births. The life expectancy of the DS population increased from 9 years original author(s) and the source, provide a link to the Creative Commons licence, and indicate if changes were made. The images or other third party material in this article are included in the article's Creative Commons licence, unless indicated otherwise in a credit line to the material. If material is not included in the article's Creative Commons licence and your intended use is not permitted by statutory regulation or exceeds the permitted use, you will need to obtain permission directly from the copyright holder. To view a copy of this licence, visit http://creativecommons.org/licenses/by/4.0/. The Creative Commons Public Domain Dedication waiver (http://creativeco mmons.org/publicdomain/zero/1.0/) applies to the data made available in this article, unless otherwise stated in a credit line to the data. 
in 1929 to 61.1 years for men with DS and 57.8 years for women with DS in 2000, due to advances in medical care, and advances in societal support [79, 107]. Increase in life expectancy resulted in an increase of the DS population $[26,66]$. However, positive changes with a significant increase of life expectancy in the DS population are associated with an increased risk of early-onset Alzheimer's disease $(\mathrm{AD})$ and dementia, exceeding $50 \%$ prior to 60 years of age and continuing to rise thereafter [52].

\section{Developmental abnormalities in the brain of DS subjects and developmental intellectual deficits}

That DS, the leading genetic cause of intellectual disability, is characterized by reduced brain size and a reduced number of neurons throughout development, points to altered neurogenesis as a major determinant of structural and functional anomalies. In the 17th to 21st gestational week $(\mathrm{GW})$, the germinal zone in the ventricle wall of DS fetuses reveals a reduced proliferation rate of progenitors of neurons involved in brain cortical mantle formation [11]. Deficits in neuron number and brain volume deficits were detected both in affected fetuses and children [11, 62, 63]. Neuropathological studies indicate that in DS, developmental defects of neurogenesis might be the main factor contributing to multiregional brain hypoplasia and functional abnormalities including cognitive impairment [57].

\section{$A D$ neuropathology and dementia in DS}

Individuals with an additional copy of chromosome 21 (trisomy 21) and DS are affected by both brain developmental abnormalities leading to intellectual deficits and early onset of Alzheimer-type neuropathology, including $\beta$-amyloidosis with diffuse and fibrillar plaque formation and amyloid angiopathy, and neurofibrillary degeneration with abnormal tau hyperphosphorylation and neurofibrillary tangle (NFT) formation common in individuals with DS older than 40 years of age $[9,30,49,70,104$, 105]. In DS subjects, further progression of neurodegeneration and neuronal loss is associated with the early onset of functional decline and dementia.

\section{Aims}

Estimation of the impact of DS developmental defects on neurogenesis leading to neuronal developmental deficit is critical for distinguishing the topography and severity of developmental deficits from mechanisms of neuronal loss caused by $\mathrm{AD}$ and other age-associated mechanisms of neuronal death.

Therefore, the first aim of this morphometric study of the brain of DS subjects was to estimate brain structure/neuronal population-specific developmental neuronal deficits in 14 brain structures and their cytoarchitectural subdivisions in 4 subjects in the preAD stage of life (26-41 years of age).

Developmental deficits were determined by estimation of the difference between the volume of selected structures and the total number of neurons in these structures in DS subjects 26-41 years of age and age matched control subjects. The second aim was to test the hypothesis that both age and stage of dementia are predictors of structural and functional decline in DS/ AD population.

The third aim was to establish trajectories of neurofibrillary degeneration, neuronal loss and volume reduction, and $\beta$-amyloidosis in an AD-positive DS cohort subdivided into those 43-49 years of age with a prevalence of mild AD, a 51-59 years of age group with a prevalence of moderate/moderately severe $\mathrm{AD}$, and a 61-72 years of age group with a prevalence of severe AD (Table 1).

Longitudinal clinical-pathological studies indicate that AD dementia is a cumulative result of multiple pathologies that contribute to lowering the threshold for clinically evident $A D$ dementia that include non$\mathrm{AD}$ cerebrovascular disease (CVD), AD-related common amyloid angiopathy [28], Lewy bodies, TDP-43 proteinopathy, and hippocampal sclerosis [35]. Therefore, the fourth aim was to expand estimates of neuronal loss as a correlate of functional decline, including $\mathrm{AD}$ dementia, with estimates of the contribution of various proteinopathies (neurofibrillary degeneration, $\alpha$-synucleinopathy with Lewy bodies, aggregation of abnormally phosphorylated TDP-43 protein, and amyloid angiopathy).

Our overall goal is to establish an age-based subclassification of $\mathrm{AD}$ pathology in early-onset $\mathrm{AD}$ in trisomic subjects with DS corresponding to the clinicopathological staging of the dynamics of pathology in late-onset $\mathrm{AD}$ (LOAD), distinguishing mild cognitive impairment (MCI)/mild AD (Functional Assessment Staging (FAST 3-4), moderate/moderately severe AD (FAST 5-6), and severe AD (FAST 7) [69, 94].

The study defined developmental volume and neuronal count deficits in 14 structures in a pre-AD group of DS subjects 26-41 years of age which delineate the difference between the baseline for onset and progression of genetically driven EOAD in DS and the baseline for sporadic LOAD. Regression analysis revealed genetically driven EOAD in the DS cohort, with strong correlations among age, stage of dementia, structure volume, neuronal count, and percentage of neurons with NFTs in almost all examined brain regions, confirming the hypothesis that both age and stage of dementia are strong predictors of structural and functional decline in the $\mathrm{DS} / \mathrm{AD}$ population. 


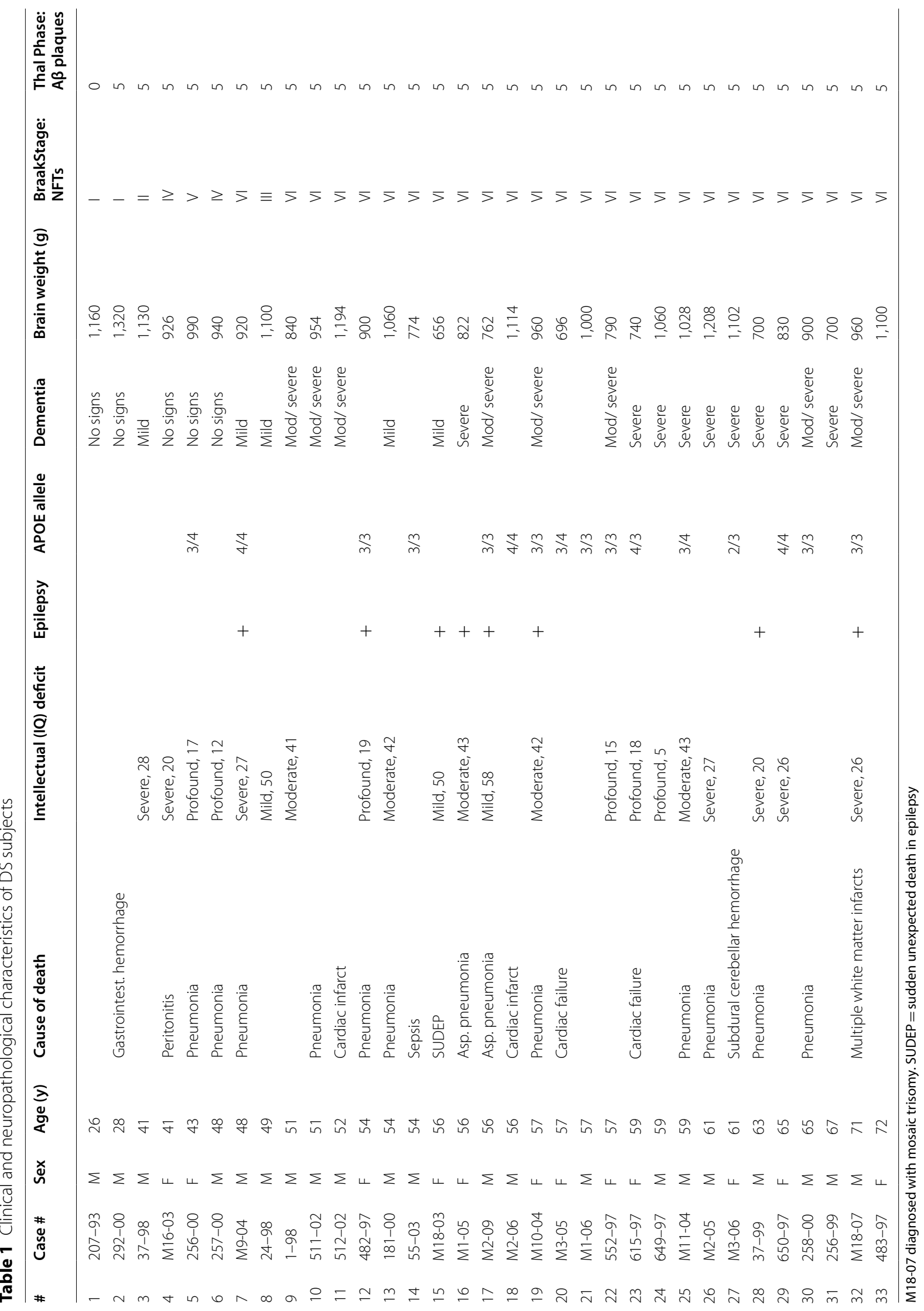




\section{Materials and methods Materials}

This study of developmental abnormalities and staging of neurodegeneration and neuronal loss in the brain of subjects with trisomy 21 and DS is the third part of our comparative study of human brain aging and loss of the neuronal reserve [93], and clinicopathological staging of LOAD [94]. Methods of tissue preservation, processing, cutting, staining, and immunostaining as well as stereological estimation of brain structure volume, number of neurons and neurons with NFTs, and amyloid load (\%) were standardized to facilitate comparison of changes in neurologically normal control subjects, subjects with LOAD, and trisomic subjects diagnosed with DS and EOAD. In this report, the material and methods described in detail in two previous reports [93, 94] are presented in an abbreviated format.

To establish the pattern of developmental neuronal deficits and AD staging of neurodegeneration and neuronal loss in DS, 33 brain hemispheres of DS subjects 26-72 years of age, $64 \%$ of whom were males and $36 \%$, females, were examined (Table 1). Samples of frozen cortex from the frontal lobe of 16 DS subjects were used for DNA extraction and APOE genotyping (LGC Genomics LLC, Alexandria, MN, USA). One or more ApoE ع4 alleles, considered a significant risk factor for dementia and $\beta$-amyloidosis $[12,65,73,76]$, were detected in $37.5 \%$ of the 16 cases genotyped $(4 / 43 x, 3 / 43 x)$, whereas the promotion of longevity and the protection of patients with DS from dementia by APOE $\varepsilon 2$ [73] was found in only one case. Diagnosis of Down syndrome trisomy 21, including one case of mosaic trisomy was extracted from subjects' medical records. Intellectual deficits ranged from mild (14\%), to moderate (24\%), severe (33\%) and profound (29\%). A history of seizures reported in eight DS subjects (24\%) in this postmortem-examined cohort was comparable to that (20.6\%) detected in individuals with DS 36 years of age and older in a study of comorbidities of 602 individuals diagnosed with DS [80].

In the 26-41-year-old group, 75\% of individuals with DS had no signs of dementia, whereas in the 43-49-yearold group $50 \%$ of subjects were free of dementia and $50 \%$ were diagnosed with mild $\mathrm{AD}$ dementia. In the 51-59-year-old group, $50.6 \%$ of individuals had moderately severe dementia, over $16 \%$ had mild dementia, and $33 \%$ had severe dementia. In the oldest group, 61-72 years of age, the percentage of subjects diagnosed with moderately severe dementia decreased to $28.6 \%$, and severe dementia increased to $71.4 \%$. In this postmortem study, the diagnosis of dementia was based on case records and caregivers' reports. In the DS cohort, the most common causes of death were pneumonia and cardiac failure. In other cases, brain infarct, subdural cerebellar hemorrhage, gastrointestinal hemorrhage, peritonitis, sepsis, and sudden unexpected epilepsy related death (SUDEP) were reported.

The control group consisted of 20 subjects, $25-78$ years of age, with no records of functional decline or dementia who were characterized in our previous report [94]. This was postmortem study without contact with subject and caregiver. This postmortem study of control group was based on donations to the New York State Brain and Tissue Bank for Developmental Disabilities and Aging at the New York State IBR, Tissue Bank for Developmental Disorders of the National Institute of Child Health and Human Development at the University of Maryland, and the Alzheimer's Disease Research Center at the New York University Grossman School of Medicine.The information about absence of functional decline was recovered from anonymized medical records. Cases with not convincing records of absence of functional decline were not included in this study.

\section{Methods of neuropathological and stereological studies}

For neuropathological studies, brain hemispheres were fixed for several months with $10 \%$ buffered formalin. Sequential 10-mm-thick coronal slabs cut with custom made macrotome were washed, dehydrated in ascending concentrations of ethyl alcohol, infiltrated with polyethylene glycol 400 (PEG; Sigma, St. Louis, MO, USA) and with PEG 1000 for two weeks, and embedded in fresh PEG 1000. Tissue blocks were cut with heavy-duty sliding microtome LEICA SM 2500 (Leica Microsystem Nussloch GmbH, Germany) into serial 50- $\mu$ m-thick sections, and enumerated free-floating sections were stored in $70 \% \mathrm{ETOH}$ [93].

For morphological and morphometric studies, serial equidistant free-floating sections were stained with cresyl violet $(\mathrm{CV})$ and used for delineation of borders of examined structures, estimation of brain structure, and anatomical subdivision volume and number of neurons. The percentage of examined structure volume occupied with monoclonal antibody (mAb) 4G8-immunopositive amyloid- $\beta$ deposits (amyloid load) was determined in sections pretreated with formic acid and incubated with mouse mAb 4G8 [36]. Sections for evaluation of neurofibrillary degeneration were pretreated with alkaline phosphatase (Sigma, type VII-L) and incubated with Tau-1 antibody $[23,93]$.

\section{Staging of topographic expansion of neurofibrillary degeneration and $\beta$-amyloidosis in DS/AD cohort}

Staging of topographic expansion of neurofibrillary degeneration in the examined DS/AD cohort was based on examination of coronal hemispheric sections immunostained with mouse monoclonal Tau-1 antibody. 
Raters applied original Braak criteria [7], distinguishing stage I with neurofibrillary degeneration in the transentorhinal cortex and entorhinal cortex (EC), stage II with spread of degeneration to the hippocampus, stage III with pathology in the temporal cortex, stage IV with expansion of tau pathology to other regions of neocortex, stage $\mathrm{V}$ with degeneration in the visual association cortex, and stage VI with degeneration in the primary visual cortex.

For staging of $\beta$-amyloidosis, sections immunostained with mAb4G8 were examined, and amyloidosis was classified by using the Thal et al. criteria [84] distinguishing five phases of topographic expansion of $A \beta$-deposition, including plaque formation limited to the neocortex (phase 1) and expansion of plaque formation to the hippocampus and amygdala (phase 2); to the diencephalic nuclei, including the putamen, the caudate nucleus $(\mathrm{CN})$, the substantia innominata, and magnocellular basal complex (MBC) of cholinergic nuclei (phase 3); to brainstem nuclei (phase 4); and to the cerebellum (phase 5).

\section{TDP43 aggregation, Lewy bodies, and amyloid angiopathy}

The focus of this subproject was the amygdala, which is the first brain structure to be affected by TDP43 aggregation and has a percentage of affected neurons that increases with age $[8,32]$. The free-floating $50-\mu \mathrm{m}$-thick sections were immunostained with rabbit polyclonal phosphorylation independent anti-TDP-43 antibody 10,782-1-AP diluted 1:500 (Protein Tech, Rosemont, Chicago, IL, USA). Estimation of TDP-43 degeneration was paralleled with estimation of the prevalence and severity of Lewy body neurodegeneration as a marker of $\alpha$-synucleinopathy. The percentage of neurons with Lewy bodies was estimated in sections immunostained with mouse mAb 4B12 detecting $\alpha$-synuclein (1:500; MA190,346, Thermo Fisher Scientific, IL, USA). To calculate the percentage of neurons with inclusions, the number of neurons estimated in adjacent cresyl violet-stained sections was considered as $100 \%$. The number of vascular profiles $\left(\mathrm{n} / \mathrm{mm}^{2}\right)$ immunopositive for $\mathrm{mAb} 4 \mathrm{G} 8$ was determined in the EC, CA1, and subiculum as well as in the molecular layer of the cerebellar cortex with prominent amyloidosis in the wall of arteries and arterioles and massive diffuse amyloid deposits.

\section{Stereological and statistical analysis}

To establish a multiregional pattern of developmental and age- and $\mathrm{AD}$-associated changes, 14 brain regions were examined, including structures found to be involved in intellectual deficits, memory loss, and a broad spectrum of functional declines. The study of the memory system included early and severely affected EC (all layers), and most affected islands of stellate neurons in the second layer delineated by using Amaral and Insausti anatomical criteria [2]. To compare patterns of pathology in different cytoarchitectural subdivisions of the hippocampus, cornu Ammonis (CA) sectors CA1, 2, 3, and 4 and the subiculum were examined by using the anatomical criteria of Rosene and van Hoesen [71] and Duvernoy [19]. The study included the dopaminergic system with all parts of the substantia nigra (SN) [20], and the acetylcholinergic system with all subdivisions of the MBC $[56,88]$. Volume and number of neurons were estimated in the entire amygdala and thalamus. Examination of the cerebellum included the volume of the molecular and granule layers to determine the total number of Purkinje cells known as free of neurofibrillary degeneration and to estimate amyloid load in the molecular layer, as well as pathology in the dentate nucleus affected by neurofibrillary degeneration but without amyloid plaques.

\section{Sampling scheme}

The procedures and parameters applied to estimates of the volume and number of neurons of each of 14 structures/anatomical subdivision are summarized in Additional file 1: Table 1. An optical fractionator systemic random sampling scheme from Stereo Investigator (MicroBrightField Inc, Vermont, USA) was applied. The mean number of equidistant sections examined per structure/per case ranged from 6 sections (amygdala four nuclei, entire thalamus, substantia nigra pars compacta and reticulata), 8 sections (all layers of the entorhinal cortex, islands of stellate neurons in the entorhinal cortex; measurements of the cerebellar molecular and granule cell layer volume used for estimation of the total number of Purkinje cells), 11 sections (for estimation of the volume and number of neurons in the magnocellular basal complex including Ch1-Ch4, and the dentate nucleus); 12 sections for stereological estimates of the subiculum, to 14 sections to estimate the volume of the caudate nucleus and the number of small neurons in the caudate nucleus. The efficiency of systematic sampling has been proposed by Gundersen et al. [25]. The number of counted neurons in individual structures ranged from 74 in the islands in the entorhinal cortex to 862 Purkinje cells. The grid size and size of the virtual counting space were adjusted to individual structure size and shape to reduce the variation reflected in the coefficient of error (CE) and standard deviation. The Scheaffer coefficient of error, decreasing with an increasing number of counted neurons, number of counting frames, and number of sections, was maintained close to the required 0.05 (MicroBrightField, Inc.) and ranged from 0.05 to 0.09 except for very small islands of stellate neurons in the entorhinal cortex with $\mathrm{CE}=0.19$. 
The volume of regions of interest and their cytoarchitectural subdivisions, the number of neurons with and without NFTs, and amyloid load were estimated with unbiased stereological methods [95] (Additional file 1: Table 1 ). The number of unaffected neurons and neurons with NFTs was estimated by using a $40 \times$ objective and final magnification of $1450 x$. The numerical density of Purkinje cells was estimated per volume of molecular and granular layer of the cerebellar cortex by using a $20 \times$ objective and $720 \times$ final magnification. Neuronal estimates were supported with stereology software (Stereo Investigator, Micro Brightfield Bioscience, Inc., Willistone, VT, USA).

Comparisons of structure volumes, number of neurons, NFTs, and amyloid load between groups were analyzed in t-tests adjusted for unequal variances when required. Linear regressions on age, stage of dementia, their interaction were used to estimate the relative degrees of association of age and stage of dementia with neuropathological characteristics. Pearson correlations are unadjusted, and significance levels are not adjusted for multiple comparisons. Analyses were performed in version 16 of Stata [22].

\section{Results}

Braak/Braak staging of neurofibrillary degeneration detected with $\mathrm{mAb}$ Tau- 1 and Thal et al. staging of topographic expansion of $\beta$-amyloidosis detected with $\mathrm{mAb}$ 4G8

In DS subjects 26-41 years of age classified in this study as in the pre-AD stage and used for the estimation of developmental deficit without or with very limited AD neuronal loss, Braak stage I of early neurofibrillary degeneration with a few affected neurons was found in two individuals 26 and 28 years of age, whereas in two subjects 41 years of age, the pathology corresponded to stages II and IV (Table 1, Figs. 1 and 2). In DS subjects 43-49 years of age classified as having mild AD, Braak stages III, IV, V, and VI of neurofibrillary degeneration were detected. In all DS subjects 51 or more years of age with prevalence of mild, moderately severe, and severe AD, the topographic pattern and severity of neurofibrillary degeneration corresponded to Braak final stage VI. $\beta$-amyloidosis was absent in a subject 26 years of age, whereas in all DS subjects 28 years of age or older, distribution of amyloid deposits matched that in Thal final phase 5 .

\section{Strong correlations between age as well as stage of dementia and declining number of neurons in DS/AD population}

Table 2 shows that the volume of the majority of examined structures, including the entorhinal cortex, the cornu Ammonis and subiculum, as well as the amygdala, thalamus, substantia nigra and magnocellular basal complex of DS subjects correlates with age as well as with stage of dementia. A regression analysisbased panel of graphs (Fig. 3) reveals that the pattern of correlations between age and a decreasing number of neurons in the entorhinal cortex, CA1, subiculum, amygdala and thalamus is very similar to the pattern of correlations between stage of dementia (no dementia, mild, moderate, and severe dementia) and the decline of the number of neurons in examined structures in the DS/AD population.
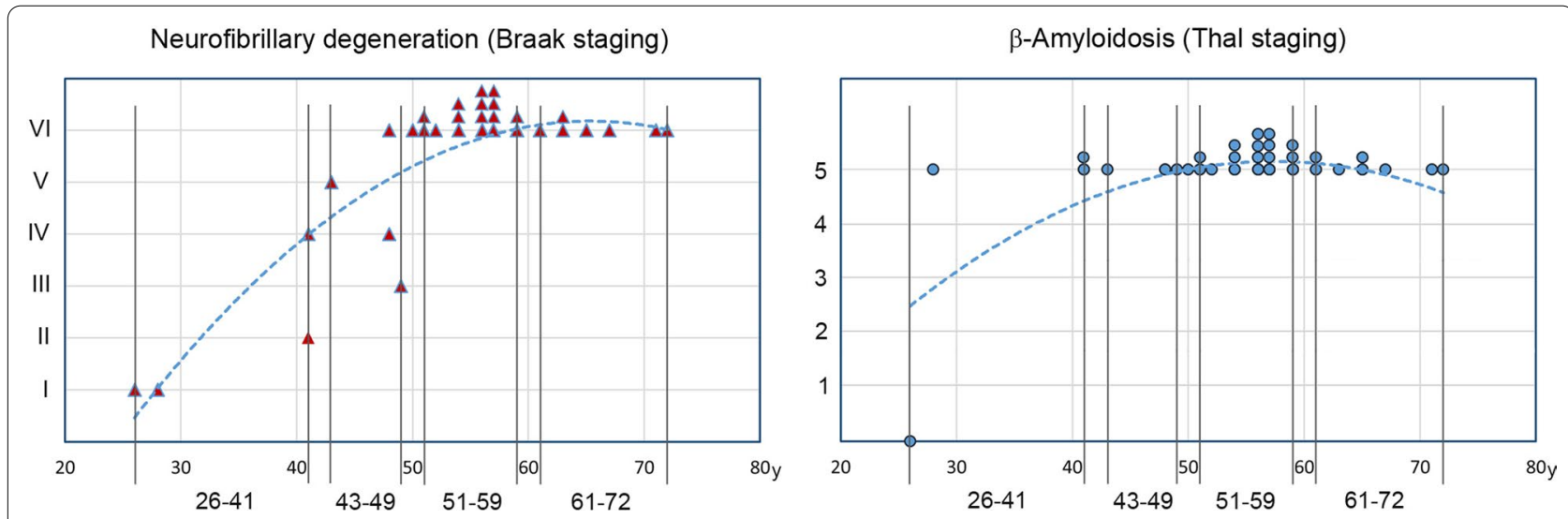

Fig. 1 Braak staging of neurofibrillary degeneration and Thal staging of $\beta$-amyloidosis. Examination of serial equidistant coronal sections stained with mAb Tau-1 detecting NFTs revealed that topographic expansion of neurofibrillary degeneration in subjects with DS results in progression from Braak stage I in 25- and 26-year-old subjects to stage VI in all subjects 51 years of age and older. The pattern of amyloid plaque distribution corresponds to Thal phase 5 in all subjects 28 years of age and older. Observed pattern reflects completion of topographic expansion at the beginning of fourth decade 


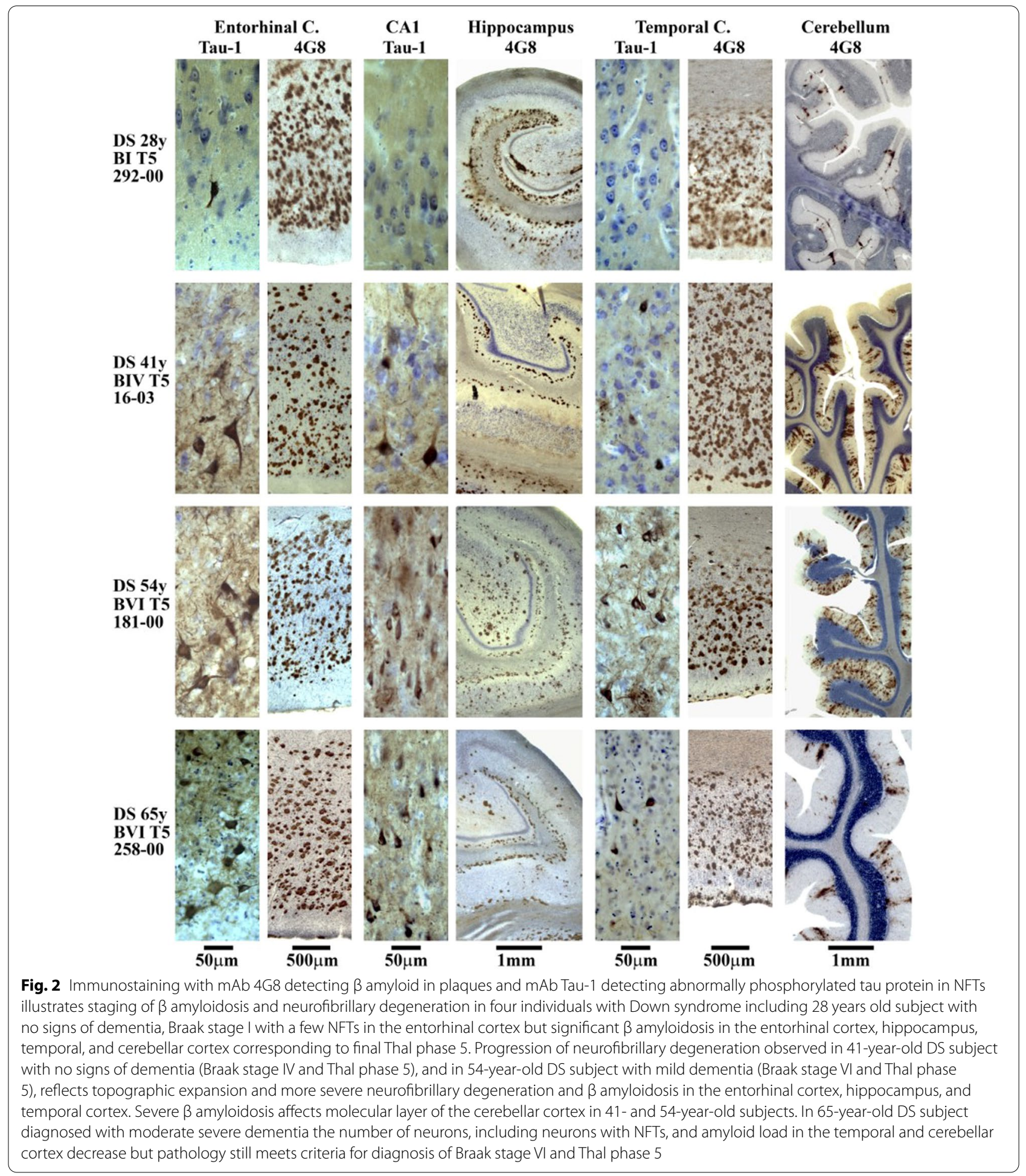

\section{Interactions between age and stage of dementia}

Figure 4 demonstrates interactions between age and stage of dementia using graphic segmentation of ageassociated neuronal decline by dementia staging in the DS cohort. The eight selected structures illustrate similarities of age and stage of dementia-associated decrease in the number of neurons in the memory system (all EC layers, EC Islands, CA1, and subiculum), 


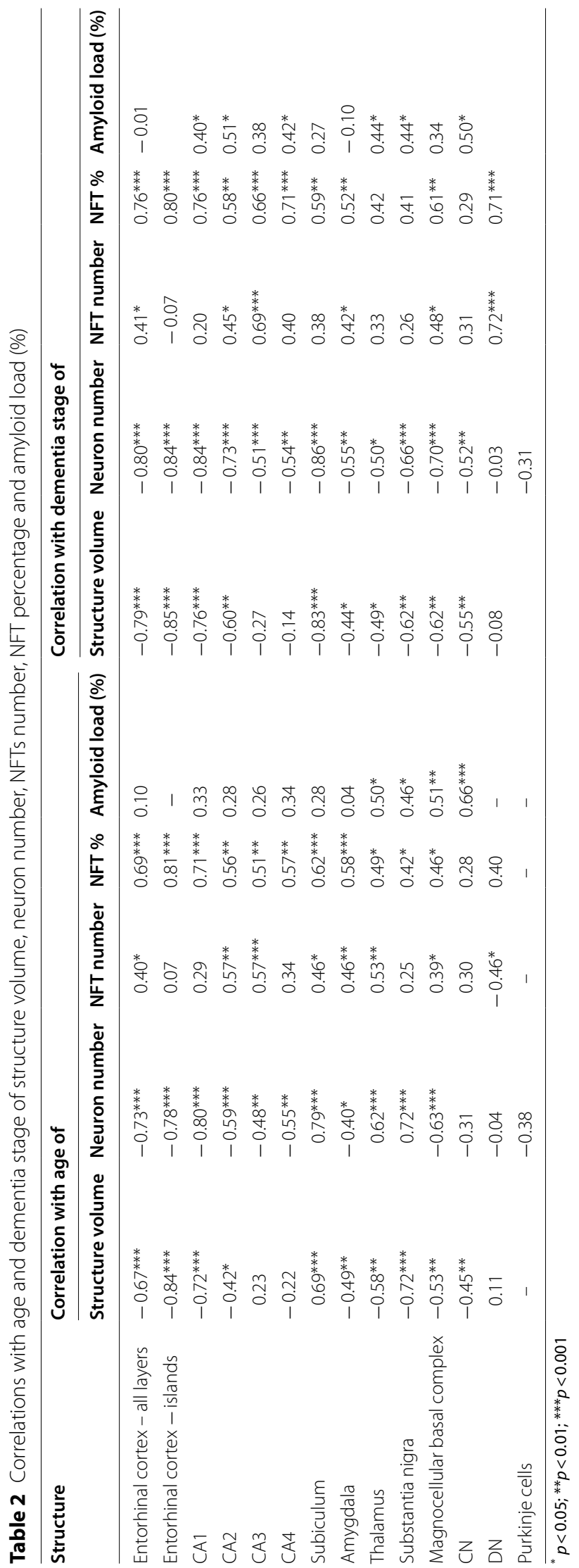



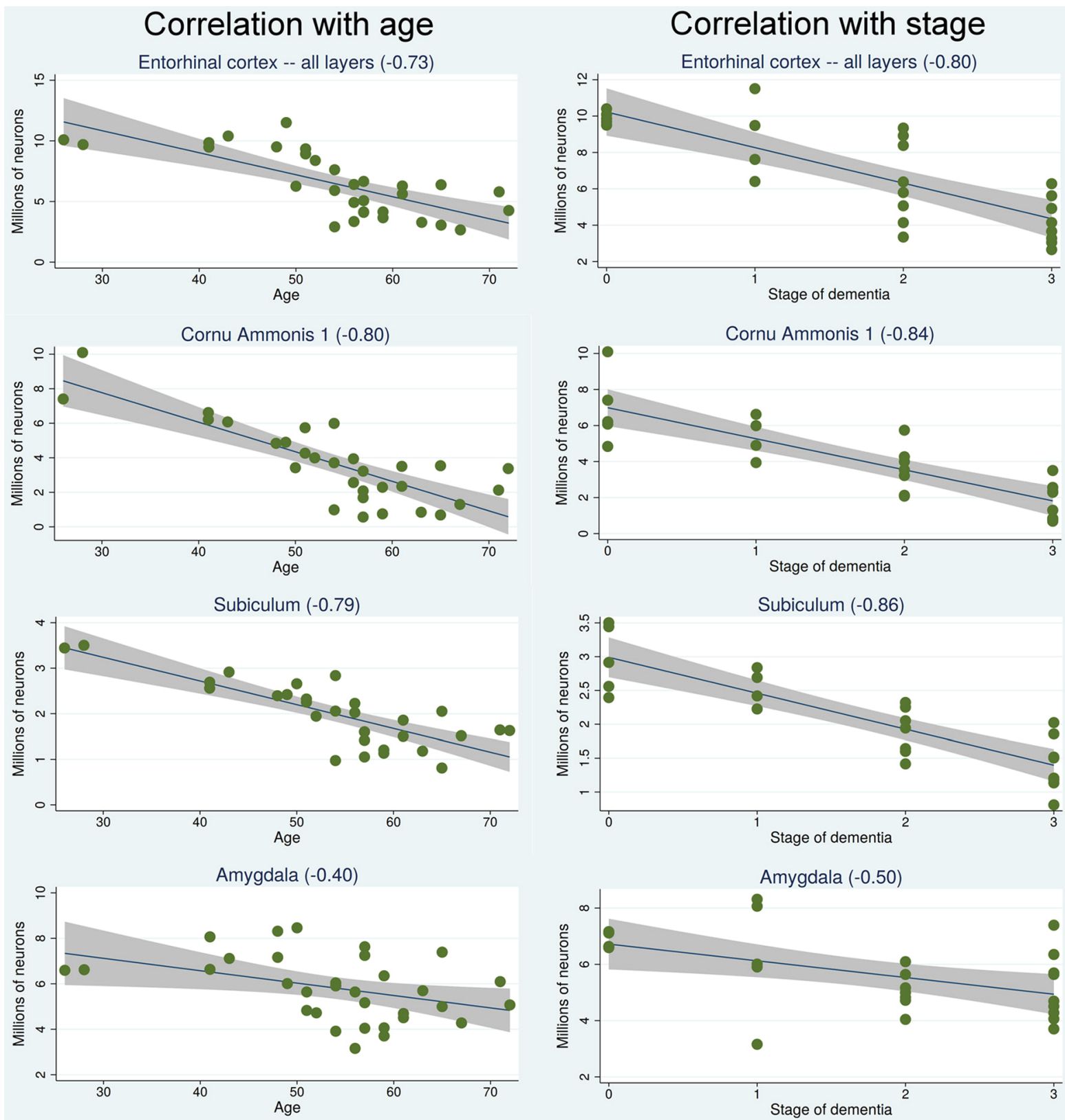

Thalamus $(-0.62)$
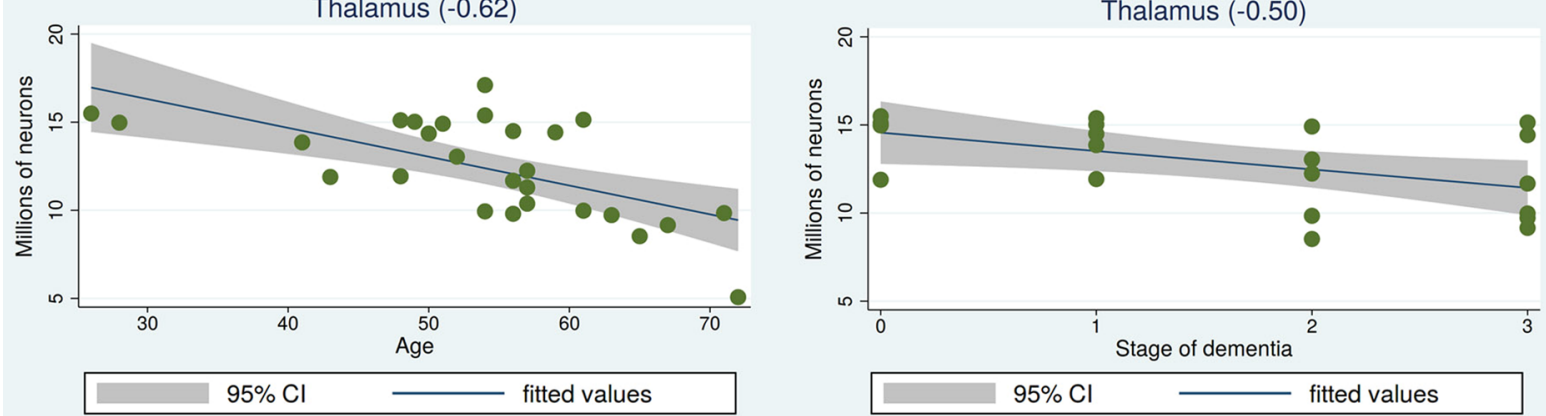

Fig. 3 Correlations between age and stage of dementia and declining number of neurons. The panel of regression analysis-based graphs reveals that both stage of dementia and age are equally strong predictors of the decreasing number of neurons in the entorhinal cortex, CA1, subiculum, amygdala, and thalamus in the DS/AD cohort. Staging of dementia: 0-no signs; 1—-mild, 2- moderately severe; 3-severe 

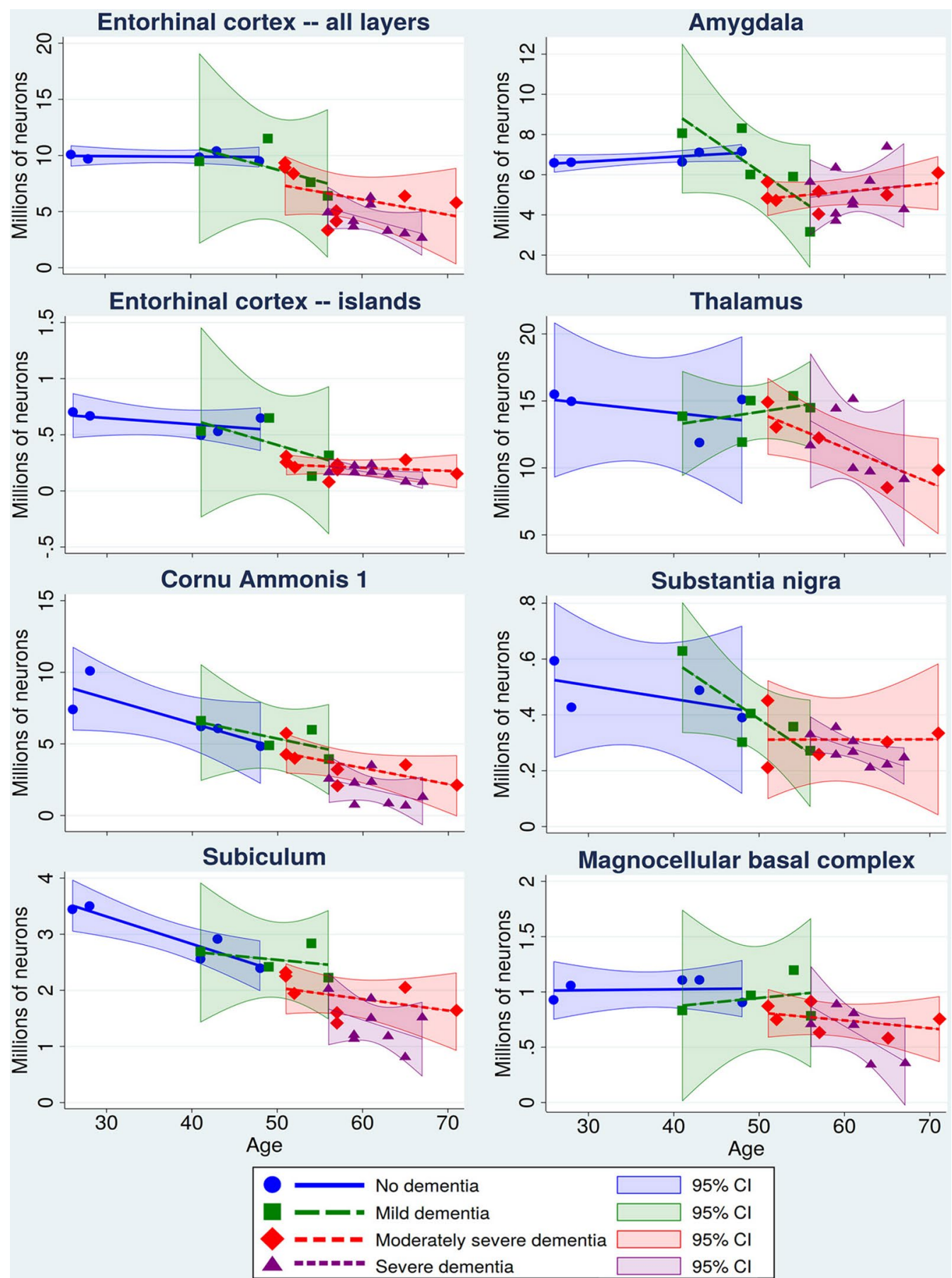

Fig. 4 Interactions of age and stage of dementia. Interactions are illustrated by a combination of scatterplots of age-associated decline in neuronal number and segmentation of the period from 26 to 72 years of age with staging of dementia in the DS cohort, including subjects with no signs of dementia and with mild, moderately severe, and severe dementia. Each of the four stages is defined by a regression-fitted line and a $95 \%$ confidence interval. Interactions are demonstrated in the entorhinal cortex (all layers), entorhinal cortex islands of stellate neurons, CA1, subiculum, amygdala, thalamus, substantia nigra and magnocellular basal complex 
amygdala and thalamus with a major contribution to functional deterioration in $\mathrm{AD}$, and two structures in the neurotransmitter systems involved in functional deterioration, including the dopaminergic system (substantia nigra) and cholinergic system (magnocellular basal complex). Graphs demonstrate segmentation of the continued process of age-associated neuronal loss for almost forty years by clinical staging identifying structure-specific patterns of neuronal decline in no dementia, mild, moderately severe, and severe dementia stages. Graphs show that despite genetic control of $\mathrm{AD}$ onset and progression, individual differences result in a broad range of age of diagnosis of dementia stages. No signs of dementia stage were diagnosed in 26-48-year-old subjects (mean age 37.2 y); mild dementia in individuals 41-56 years of age (mean 49.6 y); moderately severe dementia in 51-71-year-old subjects (mean $57.5 \mathrm{y}$ ); and severe dementia in 56-67-yearold DS subjects (mean 61.1 y) (Table 1 ).

Topography and magnitude of developmental brain structures' volume and neuronal deficits in pre-AD DS subjects 26-41 years of age

Examination of 14 brain structures revealed striking regional differences ranging from no deficit in CA2, SN,
$\mathrm{MBC}$, and $\mathrm{CN}$ to $17.0 \%$ volume deficits in the $\mathrm{EC} \mathrm{II,}$ $27.2 \%$ in CA1, $36.2 \%$ in CA4, $14.9 \%$ in the subiculum, $7.0 \%$ in the amygdala, and $17.5 \%$ in the thalamus. High developmental volume deficits were also detected in the cerebellum, including a $23.1 \%$ deficit in the dentate nucleus and a $31.6 \%$ volume deficit in the molecular layer of the cerebellar cortex (Table 3) (Fig. 5). The detected pattern of developmental deficits in the EC, hippocampal formation, amygdala, thalamus, and cerebellum indicates that in contrast to subjects with sporadic AD (sAD), in subjects with $\mathrm{DS}$, structures developing $\mathrm{AD}$-associated neurodegeneration and neuronal losses are already structurally modified by a mean $12.8 \%$ developmental volume deficit and $5,491 \mathrm{~mm}^{3}$ total volume deficit in the 14 examined brain regions.

To expand understanding of developmental deficits and $\mathrm{AD}$-associated volume losses, the numbers of neurons and neuronal deficits were estimated. Developmental neuronal deficit in 14 structures in the brain of DS subjects, estimated as the difference in the number of neurons between neurologically normal 25- to 33-year-old control subjects and 26- to 41-year-old DS subjects in the pre-AD stage, is the baseline for delineation of difference between developmental deficits and staging of ADassociated neurodegeneration and neuronal loss in DS

Table 3 Estimated developmental volume deficit in DS cohort

\begin{tabular}{|c|c|c|c|c|c|}
\hline Structure/subdivision & $\begin{array}{l}\text { Volume }\left(\mathrm{mm}^{3}\right) \text { in } \\
\text { controls } 25-43 \text { y of age } \\
(\mathrm{N}=6) \text { Mean and (SD) }\end{array}$ & $\begin{array}{l}\text { Volume }\left(\mathrm{mm}^{3}\right) \text { in } \\
\text { DS subjects } 26-41 \text { y } \\
(\mathrm{N}=4) \text { Mean and (SD) }\end{array}$ & $\begin{array}{l}\text { Volume deficit }\left(\mathrm{mm}^{3}\right) \\
\text { difference between } \\
\text { controls } 25-43 y \text { of age } \\
\text { and DS subjects } 26-41 \\
\text { y of age }\end{array}$ & Volume deficit (\%) & Volume deficit $p<$ \\
\hline $\begin{array}{l}\text { Entorhinal cortex -all } \\
\text { layers }\end{array}$ & $622.0(85.6)$ & $612.7(120.6)$ & 9.3 & 1.5 & ns \\
\hline $\begin{array}{l}\text { Entorhinal cortex- } \\
\text { islands }\end{array}$ & $38.9(6.4)$ & $32.2(8.1)$ & 6.7 & 17.0 & ns \\
\hline $\mathrm{CA} 1$ & $456.2(49.6)$ & $332.2(95.4)$ & 123.9 & 27.2 & ns \\
\hline CA2 & $30.8(4.4)$ & $42.8(15.9)$ & - & - & - \\
\hline $\mathrm{CA} 3$ & $44.7(10.9)$ & $43.2(20.9)$ & 1.4 & 3.2 & ns \\
\hline CA4 & $102.7(19.0)$ & $65.5(21.8)$ & 37.2 & 36.2 & 0.042 \\
\hline Subiculum & $184.2(19.6)$ & $156.8(34.4)$ & 27.5 & 14.9 & ns \\
\hline Amygdala & $452.0(65.1)$ & $420.5(57.1)$ & 31.5 & 7.0 & ns \\
\hline Thalamus & 3,639.7 (169.6) & $3002.7(339.2)$ & 637.1 & 17.5 & ns \\
\hline Substantia nigra & $110.0(26.8)$ & $126.3(12.2)$ & - & - & - \\
\hline $\mathrm{MBC}$ & $123.3(9.1)$ & $154.6(19.3)$ & - & - & - \\
\hline Caudate nucleus & 1,939.2 (197.4) & $2271.5(285.5)$ & - & - & - \\
\hline $\begin{array}{l}\text { Cerebellum molecular } \\
\text { layer }\end{array}$ & $14,348.0(2,412)$ & $9813.0(303.3)$ & $4,535.0$ & 31.6 & ns \\
\hline \multirow[t]{2}{*}{ Dentate nucleus } & $351.6(62.4)$ & $270.0(99.0)$ & 81.6 & 23.1 & ns \\
\hline & & & $\begin{array}{l}\text { Cumulative develop- } \\
\text { mental volume deficit: } \\
5,491.2 \mathrm{~mm}^{3}\end{array}$ & $\begin{array}{l}\text { Mean developmental } \\
\text { volume deficit: } 12.8 \%\end{array}$ & \\
\hline
\end{tabular}




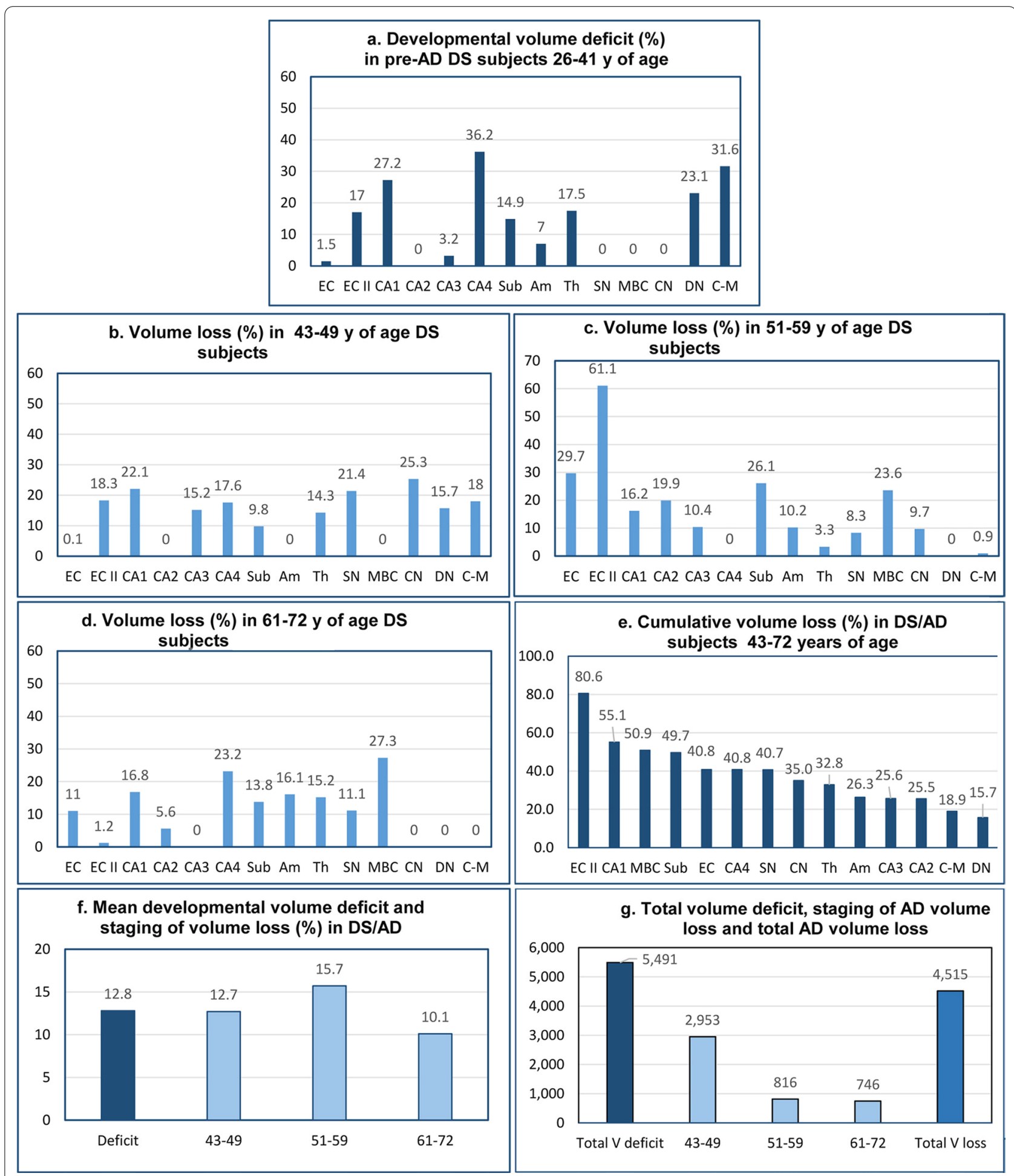

Fig. 5 Developmental volume deficits and staging of AD-associated volume loss. Developmental volume deficits in 26- to 41-year-old DS subjects show striking regional differences, with no detectable deficits in four of 14 structures, but with deficits ranging from $1.5 \%$ in the entorhinal cortex to $36.2 \%$ in CA4 (a). AD-associated volume losses are also region-specific and are more uniform in the fourth decade than in the fifth and sixth decades (b-d). Cumulative volume loss reveals a gradient of susceptibility to regional atrophy, with ECII, CA1, and MBC the most affected (e). The mean developmental volume deficit in 14 examined structures (12.8\%) is similar to mean volume losses in each of three stages of AD (f). The total developmental volume deficit $\left(5,491 \mathrm{~mm}^{3}\right)$ exceeds insignificantly the total volume loss $\left(4,515 \mathrm{~mm}^{3}\right)$ produced by three decades of AD pathology $(\mathbf{g})$ 
Table 4 Estimated developmental neuronal deficit-difference between controls 25-33 years of age and DS subjects 26-41 years of age (pre-AD stage)

\begin{tabular}{|c|c|c|c|c|c|}
\hline Structure/subdivision & $\begin{array}{l}\text { Number of neurons in } \\
\text { controls } 25-33 \text { y of age } \\
(N=4) \text { Mean and (SD) }\end{array}$ & $\begin{array}{l}\text { Number of neurons in DS } \\
\text { subjects } 26-41 \text { y of age } \\
(\mathrm{N}=4) \text { Mean and (SD) }\end{array}$ & $\begin{array}{l}\text { Neuronal deficit: } \\
\text { difference between } \\
\text { controls } 25-33 \text { y and DS } \\
\text { subjects } 26-41 \text { y of age }\end{array}$ & Neuronal deficit \% & $\begin{array}{l}\text { Neuronal } \\
\text { deficit } \\
p<\end{array}$ \\
\hline $\begin{array}{l}\text { Entorhinal cortex-all } \\
\text { layers }\end{array}$ & $11,990,000(1,774,815)$ & $9,779,100(255,051)$ & $2,210,900$ & 18.4 & ns \\
\hline Entorhinal cortex_islands & $964,696(149,494)$ & $600,288(100,952)$ & 364,408 & 37.7 & ns \\
\hline $\mathrm{CA} 1$ & $12,347,870(723,418)$ & $7,584,266(1,745,386)$ & $4,763,604$ & 38.6 & ns \\
\hline CA2 & $1,344,755(102,483)$ & $1,375,511(435,724)$ & 0 & 0 & \\
\hline CA3 & $1,265,037(411,514)$ & $1,062,288(467,225)$ & 202,749 & 16.0 & ns \\
\hline CA4 & $1,329,732(105,406)$ & $1,105,866(159,035)$ & 223,866 & 16.8 & ns \\
\hline Subiculum & $4,256,000(397,748)$ & $3,049,650(492,839)$ & $1,206,350$ & 28.3 & ns \\
\hline Amygdala & $14,192,266(2,976,788)$ & $6,978,730(724,797)$ & $7,213,356$ & 50.8 & ns \\
\hline Thalamus & $31,086,400(1,755,888)$ & $14,774,176(837,618)$ & $16,312,224$ & 52.5 & ns \\
\hline Substantia nigra & $815,726(179,515)$ & $550,053(107,611)$ & 265,673 & 32.5 & ns \\
\hline$M B C$ & $865,795(87,266)$ & $981,577(124,910)$ & 0 & 0 & \\
\hline Caudate nucleus & $41,884,561(4,548,630)$ & $41,434,112(4,788,237)$ & 450,449 & 1.1 & ns \\
\hline Purkinje cells & $21,845,212(499,288)$ & $14,247,128(2,946,322)$ & $7,598,084$ & 34.8 & ns \\
\hline \multirow[t]{2}{*}{ Dentate nucleus } & $1,528,995(267,727)$ & $510,829(26,959)$ & $1,018,166$ & 66.5 & ns \\
\hline & & & $\begin{array}{l}\text { Cumulative develop- } \\
\text { mental neuronal deficit: } \\
40,812,681\end{array}$ & $\begin{array}{l}\text { Mean developmental } \\
\text { neuronal deficit: } 28.1 \%\end{array}$ & \\
\hline
\end{tabular}

$\mathrm{MBC}=$ magnocellular basal complex

subjects 43-72 years of age (Table 4) (Fig. 6). Deficits in CA1 (38.6\%), no deficit in CA2, but $16.0 \%$ deficit in CA3, $16.8 \%$ in CA4, and $28.3 \%$ in the subiculum reflect differing severities of developmental abnormalities within parts of the same anatomical/functional complex. A $34.8 \%$ deficit of Purkinje cells and $66.5 \%$ deficit of neurons in the dentate nucleus reflect the severity of developmental deficits in the cerebellum. Deficits in the EC and the second layer of the EC $(18.4 \%$ and $37.7 \%$, respectively) as well as in CA1 (38.6\%), CA3 16.0\%), and CA4 (16.8\%) reflect pre-AD developmental deficits in structures most susceptible to early and severe AD neurodegeneration and neuronal loss. Regional diversity within the dopaminergic and cholinergic systems is reflected in a $32.5 \%$ neuronal deficit in the $\mathrm{SN}$ but the absence of a detectable deficit in the MBC. The topography and severity of developmental deficits reflect both a broad spectrum of contributions of neuronal network developmental pathology to functional deficits as well as preAD modifications affecting the course of AD pathology and the onset and course of functional decline including dementia in DS subjects.

\section{Topography and magnitude of AD-associated volume loss in DS subjects}

A $12.7 \%$ mean volume loss was detected in 43- to 49-year-old DS subjects (Table 5, Fig. 5), but this loss was extended by an additional $15.7 \%$ mean volume loss in 51-59-year-old DS subjects with a prevalence of moderately severe $\mathrm{AD}$ and by an additional $10.1 \%$ loss in

(See figure on next page.)

Fig. 6 Developmental neuronal deficits and staging of AD-associated neuronal loss. Graphs characterize region-specific developmental neuronal deficits (a) as well as region-specific neuronal loss in the fourth, fifth, and sixth decades of life of DS subjects (b, $\mathbf{c}$, $\mathbf{d}$, respectively). Cumulative neuronal loss reveals the gradient of different susceptibilities to neurodegeneration and neuronal death reflected in neuronal losses, ranging from $18.4 \%$ in the dentate nucleus to $73.9 \%$ in the second layer of the entorhinal cortex (e). Developmental deficit of neurons in examined structures is estimated as $28.1 \%$, whereas percentage of lost neurons increases from $11.9 \%$ in fourth decade to top level (28.0\%) in fifth decade and decreases to bottom level (11.0\%) in sixth decade of life of DS subjects (f). The measure of dynamic of AD-associated neuronal loss is the top level of neuronal loss (20.4 million) in the early stage (fourth decade) and the decline of neuronal loss to 13.4 million in the fifth decade and further decline to the lowest level (7.7 million) in the sixth decade (g). Surprisingly, the estimated total developmental deficit of neurons (40.8 million) contributing to developmental intellectual deficits is almost identical with the total neuronal loss (41.6 million) contributing to AD-associated dementia in DS subjects (h) 


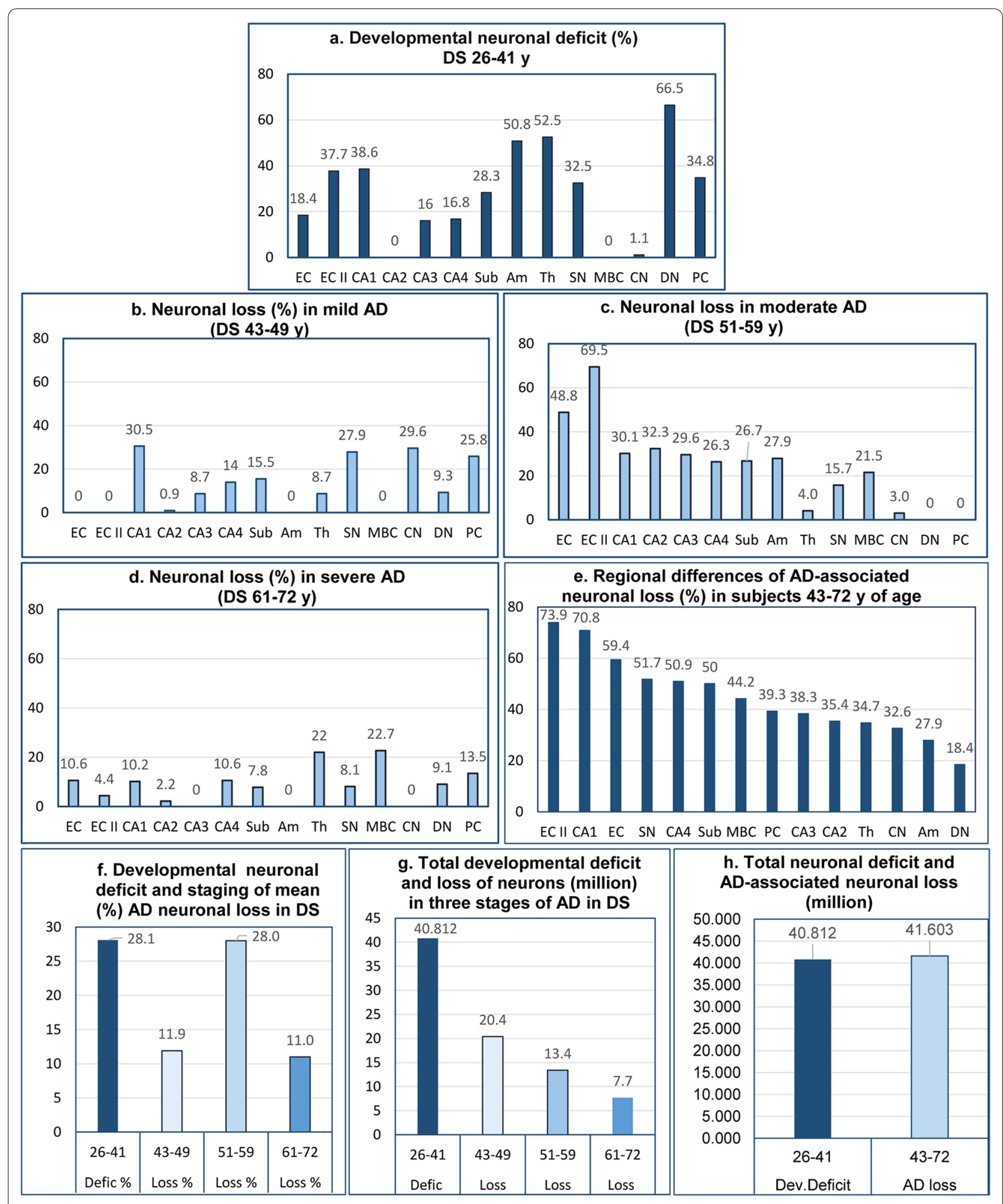

Fig. 6 (See legend on previous page.) 
Table 5 Estimated AD-associated volume loss ( $\mathrm{mm}^{3}$ and \%) in three age/AD stages in DS

\begin{tabular}{|c|c|c|c|c|c|c|c|c|c|}
\hline \multirow[t]{2}{*}{$\begin{array}{l}\text { Structure/ } \\
\text { subdivision }\end{array}$} & \multicolumn{3}{|c|}{$\begin{array}{l}\text { Volume loss in } 43 \text { - to } 49 \text {-y- old DS } \\
\text { subjects, } N=4 \text { (no signs or mild } \\
\text { dementia) }\end{array}$} & \multicolumn{3}{|c|}{$\begin{array}{l}\text { Volume loss in 51-to 59-y-old DS } \\
\text { subjects, } N=17 \text { (prevalence of } \\
\text { moderately severe dementia) }\end{array}$} & \multicolumn{3}{|c|}{$\begin{array}{l}\text { Volume lost in } 61 \text {-to } 72 \text { - } y \text { - old DS } \\
\text { subjects, } N=8 \text { (prevalence of severe } \\
\text { dementia) }\end{array}$} \\
\hline & $\begin{array}{l}\text { Volume- } \\
\text { difference } \\
\text { between } \\
26-41 \text { y and } \\
43-49 \text { y old }\end{array}$ & $\begin{array}{l}\text { Volume loss } \\
\text { (\%) }\end{array}$ & $p<$ & $\begin{array}{l}\text { Volume } \\
\text { difference } \\
\text { between } \\
43-49 \text { y and } \\
51-59 \text { y old }\end{array}$ & $\begin{array}{l}\text { Volume loss } \\
\text { (\%) }\end{array}$ & $p<$ & $\begin{array}{l}\text { Volume } \\
\text { difference } \\
\text { between } \\
51-59 \text { y and } \\
61-72 \text { y old }\end{array}$ & $\begin{array}{l}\text { Volume loss } \\
\text { (\%) }\end{array}$ & $p<$ \\
\hline $\begin{array}{l}\text { Entorhinal } \\
\text { cortex-—all } \\
\text { layers }\end{array}$ & 0.3 & 0.1 & ns & 181.8 & 29.7 & $0.0001^{* * *}$ & 67.6 & 11.0 & $0.036^{*}$ \\
\hline $\begin{array}{l}\text { Entorhinal cor- } \\
\text { tex-islands }\end{array}$ & 5.9 & 18.3 & ns & 19.7 & 61.1 & $0.0001^{* * *}$ & 0.4 & 1.2 & ns \\
\hline CA1 & 73.6 & 22.1 & $0.009^{* *}$ & 53.9 & 16.2 & $0.036^{*}$ & 56.0 & 16.8 & $0.005^{* *}$ \\
\hline CA2 & 0.0 & 0.0 & - & 8.5 & 19.9 & $0.014^{*}$ & 2.4 & 5.6 & ns \\
\hline CA3 & 6.6 & 15.2 & ns & 4.5 & 10.4 & ns & - & 0.0 & ns \\
\hline CA4 & 11.5 & 17.6 & $0.045^{*}$ & - & - & - & 15.2 & 23.2 & ns \\
\hline Subiculum & 15.4 & 9.8 & $0.022^{*}$ & 41.0 & 26.1 & $0.002^{* *}$ & 21.7 & 13.8 & $0.036^{*}$ \\
\hline Amygdala & - & - & - & 43.0 & 10.2 & $0.050^{*}$ & 67.6 & 16.1 & $0.005^{* *}$ \\
\hline Thalamus & 427.9 & 14.3 & ns & 101.1 & 3.3 & ns & 459.1 & 15.2 & $0.036^{*}$ \\
\hline $\begin{array}{l}\text { Substantia } \\
\text { nigra }\end{array}$ & 27.1 & 21.4 & $0.0009^{* * *}$ & 10.6 & 8.3 & $0.035^{*}$ & 14.0 & 11.1 & $0.034^{*}$ \\
\hline$M B C$ & - & - & - & 36.5 & 23.6 & $0.009^{* *}$ & 42.3 & 27.3 & $0.007^{* *}$ \\
\hline $\begin{array}{l}\text { Caudate } \\
\text { nucleus }\end{array}$ & 575.3 & 25.3 & ns & 222.0 & 9.7 & ns & - & 0.0 & ns \\
\hline $\begin{array}{l}\text { Cerebellar cor- } \\
\text { tex: molecular } \\
\text { and granule } \\
\text { cells layer }\end{array}$ & 1767.0 & 18.0 & $0.033^{*}$ & 93.3 & 0.9 & ns & - & 0.0 & ns \\
\hline \multirow{2}{*}{$\begin{array}{l}\text { Dentate } \\
\text { nucleus }\end{array}$} & 42.5 & 15.7 & & - & - & - & - & - & - \\
\hline & $\begin{array}{l}\text { Cumulative } \\
\text { volume loss in } \\
43-49 \text { y of age } \\
\text { DS subjects: } \\
2,953.1 \mathrm{~mm}^{3}\end{array}$ & $\begin{array}{l}\text { Mean volume } \\
\text { loss: } 12.7 \%\end{array}$ & & $\begin{array}{l}\text { Cumulative } \\
\text { volume loss in } \\
51-59 \text { y of age } \\
\text { DS subjects: } \\
816.0 \mathrm{~mm}^{3}\end{array}$ & $\begin{array}{l}\text { Mean volume } \\
\text { loss: } 15.7 \%\end{array}$ & & $\begin{array}{l}\text { Cumulative } \\
\text { volume loss in } \\
61-72 \text { y of age } \\
\text { DS subjects: } \\
746.3 \mathrm{~mm}^{3}\end{array}$ & $\begin{array}{l}\text { Mean volume } \\
\text { loss: } 10.1 \%\end{array}$ & \\
\hline
\end{tabular}

Structure-specific AD-associated volume loss (\%) calculated in all three stages/age groups in reference to baseline volume in DS subjects $26-41$ years of age (100\%) who are affected by developmental deficits but not, or in limited range, by pre-AD pathology. ${ }^{*} p<0.05 ;{ }^{* *} p<0.01 ;{ }^{* * *} p<0.001$

$\mathrm{MBC}=$ magnocellular basal complex

Volume of the molecular and granule cells layer of the cerebellar cortex was measured to estimate total number of Purkinje cells dispersed in the border zone between these layers

61-72-year-old subjects with a prevalence of severe AD. Examination of 14 brain structures in three age groups revealed strikingly different volume losses in individual structures and different stages of $\mathrm{AD}$, including $18.3 \%$ volume loss in the ECII in the 43-49-year-old group, $61.1 \%$ loss in the 51-59-year-old group, but only $1.2 \%$ in the 61-72-year-old group with severe AD. The opposite trend is observed in the amygdala, with undetectable volume loss in the fourth decade of life, but $10.2 \%$ loss in the 5 th decade and $16.1 \%$ loss in the sixth decade. Structures with undetectable volume developmental deficit reveal prominent losses in the $4^{\text {th }}$ decade, including the
SN (21.4\%), CN (25.3\%), and cerebellar molecular layer $(18 \%)$, with a decrease in the percentage of volume loss in the $5^{\text {th }}$ and $6^{\text {th }}$ decades.

A measure of structure-specific differences of $\mathrm{AD}$ pathology is the cumulative volume loss in AD in DS subjects $43-72$ years of age, varying from $40.8 \%$ in all layers of the EC to $80.6 \%$ in the EC's second layer of stellate neurons; from $25.6 \%$ in CA3 to $55.1 \%$ in CA1, $26.3 \%$ in the amygdala, $32.8 \%$ in the thalamus, $35.0 \%$ in the $\mathrm{CN}, 40.7 \%$ in the $\mathrm{SN}$, and $50.9 \%$ in the MBC (Fig. 5).

The cumulative mean percentages of volume loss for all examined structures in $43-$ to $49-, 51$ - to 59-, 
and 61- to 72-year-old DS subjects are relatively similar $(12.7 \%, 15.7 \%$, and $10.1 \%$, respectively). However, estimates of $\mathrm{AD}$-associated total volume loss $\left(\mathrm{mm}^{3}\right)$ reveal differences, with the most severe volume loss in the youngest group (43-49 years of age) $\left(2,953 \mathrm{~mm}^{3}\right)$, a $3.6 \times$ lower volume loss in 51- to 59-year-old subjects $\left(816 \mathrm{~mm}^{3}\right)$, and the lowest volume loss $\left(746 \mathrm{~mm}^{3}\right)$ in 61- to 72-year-old subjects with a prevalence of severe AD (Fig. 5).

The difference in volume between developmental deficits and $\mathrm{AD}$-associated changes is reflected in a ratio between the $5,491 \mathrm{~mm}^{3}$ total developmental volume deficit in 26- to 41-year-old DS subjects and the 4,515 $\mathrm{mm}^{3}$ volume loss during the 29-year duration of AD in DS subjects 43-72 years of age. This pattern reflects the contribution of developmental pathological processes to lifetime intellectual deficits and cognitive decline and dementia in 43- to 72-year-old subjects diagnosed with $\mathrm{AD}$.

\section{Staging of AD-associated neuronal loss in DS subjects}

Neuronal loss in mild AD in DS was estimated as the difference between the number of neurons in
pre-AD DS subjects 26-41 years of age and DS/AD subjects 43-49 years of age. To estimate neuronal loss in each age stage of $\mathrm{AD}$, the difference in the number of neurons between 43-49 and 51-59 years of age, and 51-59 and 61-72 years of age was calculated. The percentage of neuronal loss was calculated in reference to the number of neurons in the pre-AD DS subjects 26-41 years of age (100\%) (Table 6).

\section{Incipient stage of neuronal loss in 43- to 49-year-old DS subjects}

The prominent features of neuronal loss in 43- to 49-year-old DS subjects with prevalence of mild AD were the striking differences between examined structures (Table 6, Fig. 6). Neuronal loss in this age group had features of the incipient stage with a surprising absence of neuronal loss in the $\mathrm{EC}$, the second layer of the $\mathrm{EC}$, the amygdala, and $\mathrm{MBC}$, and variable neuronal loss in all CA sectors, ranging from $0.9 \%$ in the CA2 to $30.5 \%$ in the CA1 and $15.5 \%$ in the subiculum. Equally surprising is the $25.8 \%$ loss of Purkinje cells not developing neurofibrillary degeneration, the $29.6 \%$ loss of neurons in

Table 6 Estimated AD-associated neuronal loss in 43-49-yr-old DS subjects (loss per day and per million neurons/day)

\begin{tabular}{|c|c|c|c|c|c|c|c|}
\hline $\begin{array}{l}\text { Structures/ } \\
\text { subdivisions }\end{array}$ & $\begin{array}{l}\text { Number of neurons } \\
\text { in } 26-\text { to } 41 \text {-y-old DS } \\
\text { subjects } N=4 \text {, Mean } \\
\text { and (SD) }\end{array}$ & $\begin{array}{l}\text { Number of neurons } \\
\text { in } 43 \text { - to } 49-y \text {-old } \\
\text { DS subjects } N=4 \text {, } \\
\text { Mean and (SD) }\end{array}$ & $\begin{array}{l}\text { Neurons lost (vs. } \\
26 \text {-to } 41 \text {-y- old DS } \\
\text { subjects) }\end{array}$ & Neurons lost (\%) & $P<$ & $\begin{array}{l}\text { Number of } \\
\text { neurons } \\
\text { lost/day }\end{array}$ & $\begin{array}{l}\text { Number of } \\
\text { neurons } \\
\text { lost/ } \\
\text { million/day }\end{array}$ \\
\hline $\begin{array}{l}\text { Entorhinal cortex-all } \\
\text { layers }\end{array}$ & $9,779,100(255,051)$ & $10,470,333(1,003,992)$ & 0.0 & 0.0 & & 0 & \\
\hline $\begin{array}{l}\text { Entorhinal cortex- } \\
\text { islands }\end{array}$ & $600,288(100,952)$ & $609,481(68,719)$ & 0.0 & 0.0 & & 0 & \\
\hline CA1 & $7,584,266(1,745,386)$ & $5,271,466(699,001)$ & $2,312,800$ & 30.5 & ns & 487.4 & 64.3 \\
\hline CA2 & $1,375,511(435,724)$ & $1,363,407(350,731)$ & 12,104 & 0.9 & ns & 2.6 & 1.9 \\
\hline CA3 & $1,062,288(467,225)$ & $969,837(225,781)$ & 92,451 & 8.7 & ns & 19.5 & 18.3 \\
\hline CA4 & $1,105,866(159,035)$ & $950,304(255,206)$ & 155,562 & 14.0 & ns & 32.8 & 29.6 \\
\hline Subiculum & $3,049,650(492,839)$ & $2,575,933(293,733)$ & 473,717 & 15.5 & ns & 99.8 & 32.7 \\
\hline Amygdala & $6,978,730(724,797)$ & $7,150,380(940,312)$ & 0.0 & 0.0 & & 0 & 0 \\
\hline Thalamus & $14,774,176(837,618)$ & $13,488,304(1,821,914)$ & $1,285,871$ & 8.7 & ns & 271.0 & 18.3 \\
\hline Substantia nigra & $550,053(107,611)$ & $396,519(76,289)$ & 135,534 & 27.9 & ns & 32.4 & 58.8 \\
\hline $\mathrm{MBC}$ & $981,577(124,910)$ & $994,389(104,089)$ & 0.0 & 0.0 & & 0 & 0 \\
\hline Caudate nucleus & $41,434,112(4,788,237)$ & $29,151,928(7,214,428)$ & $12,282,183$ & 29.6 & $0.03^{*}$ & $2,588.4$ & 62.5 \\
\hline Purkinje cells & $14,247,128(2,946,322)$ & $10,569,930(720,445)$ & $3,677,198$ & 25.8 & ns & 775.0 & 54.4 \\
\hline \multirow[t]{2}{*}{ Dentate $\mathrm{n}$} & $510,829(26,959)$ & $463,150(138,022)$ & 47,679 & 9.3 & ns & 10.0 & 19.7 \\
\hline & & & $\begin{array}{l}\text { Total loss: 20,475,099 } \\
\text { neurons }\end{array}$ & Mean loss: $11.9 \%$ & & $\begin{array}{l}\text { Mean loss } \\
308.4 / d \\
\text { Total loss } \\
4,318.9 / d\end{array}$ & $\begin{array}{l}\text { Mean loss } \\
25.7 / \text { million/ } \\
\text { day }\end{array}$ \\
\hline
\end{tabular}

Losses per day and per million neurons per day were calculated using the 13-year (4,745-day) difference in mean age between the groups as the dominator " $p<.05$ 
the $\mathrm{CN}$ with mild neurofibrillary degeneration, and the $27.9 \%$ loss in the SN with neurofibrillary degeneration and $\beta$-amyloidosis.

\section{Ceiling level of the percentage of neuronal loss in 51- to 59-year-old DS subjects}

The pattern of neuronal loss in moderate AD in 51- to 59-year-old DS subjects reflects a ceiling level of neuronal loss, essential for AD, in all layers of the EC (48.8\%) and the second layer of the EC (69.5\%), severe losses in all CA sectors (from $26.3 \%$ in CA4 to $30.1 \%$ in CA1 and $32.3 \%$ in CA2), and $26.7 \%$ loss in the subiculum, paralleled with a $27.9 \%$ loss in the amygdala and a $21.5 \%$ loss in the MBC (Table 7, Fig. 6).
Decline of neuronal loss in 61- to 72-year-old DS subjects with prevalence of severe dementia

A $4.6 \times$ and $15.7 \times$ decline of neuronal loss in the $\mathrm{EC}$ and the second layer of the EC, respectively, a $14.6 \times$ decline in the CA2 and reduction of neuronal loss from $29.6 \%$ in CA3 in 5 th decade to 0 in sixth decade, and a $28 \times$ decline in the amygdala in the 5 th and 6th decades reflect depletion of the pool of neurons during the 16 years of mild and moderate AD in DS subjects 43-59 years of age. However, although the majority of examined structures reveal a floor level in the 61-72-year-old group (Table 8, Fig. 6), the thalamus shows a local increase in neuronal loss from $4.03 \%$ to $22.0 \%$, whereas the MBC shows a plateau with $21.5 \%$

Table 7 Estimated AD-associated neuronal loss in 51-to 59-y-old DS subjects (loss per day and per million neurons/day)

\begin{tabular}{|c|c|c|c|c|c|c|c|c|}
\hline $\begin{array}{l}\text { Structures/ } \\
\text { subdivisions }\end{array}$ & $\begin{array}{l}\text { Number of } \\
\text { neurons in } 43- \\
\text { to } 49-y-\text { old DS } \\
\text { subjects, } N=4, \\
\text { Mean and (SD) }\end{array}$ & $\begin{array}{l}\text { Number of } \\
\text { neurons in } \\
51 \text {-to } 59 \text {-yr-old } \\
\text { DS subjects, } \\
N=17, \text { Mean } \\
\text { and (SD) }\end{array}$ & $\begin{array}{l}\text { Neurons lost. } \\
\text { difference } \\
\text { between } 43-\text { to } \\
49 \text { and } 51-\text { to } \\
59-y-\text {-old DS } \\
\text { subjects }\end{array}$ & $\begin{array}{l}\text { Number of } \\
\text { neurons in } \\
\text { DS reference } \\
\text { group 26-to } \\
41-y-\text {-old } \\
(100 \%)\end{array}$ & $\begin{array}{l}\text { Neurons } \\
\text { lost }(\%) \text { in } \\
51-59-y-\text { old } \\
\text { DS subjects } \\
\text { reference } \\
\text { group, 26-to } \\
41-y-\text { old }\end{array}$ & $P<$ & $\begin{array}{l}\text { Number of } \\
\text { neurons } \\
\text { lost/day }\end{array}$ & $\begin{array}{l}\text { Number of } \\
\text { neurons lost/ } \\
\text { million/day }\end{array}$ \\
\hline $\begin{array}{l}\text { Entorhinal c.all } \\
\text { layers }\end{array}$ & $\begin{array}{l}10,470,333 \\
(1,003,992)\end{array}$ & $\begin{array}{l}5,702,533 \\
(2,101,830)\end{array}$ & $4,767,800$ & $9,779,100$ & 48.8 & $0.002^{* * *}$ & 1520.8 & 145.3 \\
\hline $\begin{array}{l}\text { Entorhinal c. } \\
\text { islands }\end{array}$ & $609,481(68,719)$ & $192,314(84,474)$ & 417,167 & 600,288 & 69.5 & $0.001^{* * *}$ & 133.1 & 218.3 \\
\hline CA1 & $\begin{array}{l}5,271,466 \\
(699,001)\end{array}$ & $\begin{array}{l}2,986,260 \\
(1,727,048)\end{array}$ & $2,285,206$ & $7,584,266$ & 30.1 & $0.05^{*}$ & 728.9 & 138.3 \\
\hline CA2 & $\begin{array}{l}1,363,407 \\
(350,731)\end{array}$ & $\begin{array}{l}919,574 \\
(287,449)\end{array}$ & 443,833 & $1,375,511$ & 32.3 & $0.04^{*}$ & 141.6 & 103.8 \\
\hline CA3 & $\begin{array}{l}969,837 \\
(225,781)\end{array}$ & $\begin{array}{l}655,428 \\
(255,405)\end{array}$ & 314,409 & $1,062,288$ & 29.6 & ns & 100.3 & 103.4 \\
\hline CA4 & $\begin{array}{l}950,304 \\
(255,206)\end{array}$ & $\begin{array}{l}658,923 \\
(467,298)\end{array}$ & 291,381 & $1,105,866$ & 26.3 & ns & 92.9 & 97.8 \\
\hline Subiculum & $\begin{array}{l}2,575,933 \\
(293,733)\end{array}$ & $\begin{array}{l}1,760,757 \\
(562,251)\end{array}$ & 815,176 & $3,049,650$ & 26.7 & $0.03^{*}$ & 260.0 & 100.9 \\
\hline Amygdala & $\begin{array}{l}7,150,380 \\
(940,312)\end{array}$ & $\begin{array}{l}5,203,993 \\
(1,311,409)\end{array}$ & $1,946,387$ & $6,978,730$ & 27.9 & $0.02^{*}$ & 620.9 & 86.8 \\
\hline Thalamus & $\begin{array}{l}13,488,304 \\
(1,821,914)\end{array}$ & $\begin{array}{l}12,891,781 \\
(2,374,425)\end{array}$ & 596,524 & $14,774,176$ & 4.0 & ns & 190.3 & 14.1 \\
\hline Substantia nigra & $396,519(76,289)$ & $309,905(65,494)$ & 86,614 & 550,053 & 15.7 & $0.05^{*}$ & 27.6 & 69.7 \\
\hline $\mathrm{MBC}$ & $\begin{array}{l}994,389 \\
(104,089)\end{array}$ & $\begin{array}{l}783,233 \\
(205,770)\end{array}$ & 211,156 & 981,577 & 21.5 & ns & 67.4 & 67.7 \\
\hline Caudate n & $\begin{array}{l}29,151,928 \\
(7,214,428)\end{array}$ & $\begin{array}{l}27,913,089 \\
(10,600,000)\end{array}$ & $1,238,840$ & $41,434,112$ & 3.0 & $\mathrm{~ns}$ & 395.2 & 13.6 \\
\hline Purkinje cells & $\begin{array}{l}10,569,930 \\
(720,445)\end{array}$ & $\begin{array}{l}11,715,680 \\
(2,207,151)\end{array}$ & 0 & $14,247,128$ & & & & \\
\hline \multirow[t]{2}{*}{ Dentate $n$} & $\begin{array}{l}463,150 \\
(138,022)\end{array}$ & $520,173(96,537)$ & 0 & 510,829 & & & & \\
\hline & & & $\begin{array}{l}\text { Total loss: } \\
13,414,493 \\
\text { neurons }\end{array}$ & & $\begin{array}{l}\text { Mean loss: } \\
28.0 \%\end{array}$ & & $\begin{array}{l}\text { Mean loss: } \\
\text { 356.6/d } \\
\text { Total loss: } \\
\text { 4,278.9/d }\end{array}$ & $\begin{array}{l}\text { Mean loss: } 96.6 / \\
\text { million/d }\end{array}$ \\
\hline
\end{tabular}

Loss calculated using the 8.6-year $\left(3,135\right.$-day) difference in mean age between the groups as the denominator. ${ }^{*} p<0.05$; ${ }^{* *} p<0.01 ;{ }^{* * *} p<0.001$ 
Table 8 Estimated AD-associated neuronal loss in 61-72-y-old DS subjects (loss per day and per million neurons/day)

\begin{tabular}{|c|c|c|c|c|c|c|c|c|}
\hline $\begin{array}{l}\text { Structures/ } \\
\text { subdivisions }\end{array}$ & $\begin{array}{l}\text { Number of } \\
\text { neurons in } \\
51-\text { to } 59 \text {-y-old } \\
D S \text { subjects, } \\
N=17 \text {, Mean } \\
\text { (SD) }\end{array}$ & $\begin{array}{l}\text { Number of } \\
\text { neurons in } \\
61 \text {-to } 72 \text {-y-old } \\
\text { DS subjects, } \\
N=8 \text { Mean } \\
\text { (SD) }\end{array}$ & $\begin{array}{l}\text { Neurons lost. } \\
\text { Difference } \\
\text { between } 51 \text {-to } \\
59 \text { and } 61 \text { - to } \\
72 \text {-y-old DS } \\
\text { subject }\end{array}$ & $\begin{array}{l}\text { Number of } \\
\text { neurons in } \\
\text { DS reference } \\
\text { group 26-to } \\
41-y-\text {-old } \\
\text { (100\%) DS } \\
\text { subjects }\end{array}$ & $\begin{array}{l}\text { Neurons } \\
\text { lost (\%) in } \\
61-72-y \text {-old } \\
\text { DS subjects. } \\
\text { Reference } \\
\text { group }(100 \%) \\
26 \text {-to } 41-y \text {-old }\end{array}$ & $P<$ & $\begin{array}{l}\text { Number of } \\
\text { neurons } \\
\text { lost/day }\end{array}$ & $\begin{array}{l}\text { Number of } \\
\text { neurons lost/ } \\
\text { million/day }\end{array}$ \\
\hline $\begin{array}{l}\text { Entorhinal c. -all } \\
\text { layers }\end{array}$ & $\begin{array}{l}5,702,533 \\
(2,101,830)\end{array}$ & $\begin{array}{l}4,666,150 \\
(1,533,640)\end{array}$ & $1,036,383$ & $9,779,100$ & 10.6 & ns & 282.9 & 49.6 \\
\hline $\begin{array}{l}\text { Entorhinal c. } \\
\text {-islands }\end{array}$ & $192,314(84,474)$ & $165,633(68,200)$ & 26,681 & 600,288 & 4.4 & ns & 7.3 & 37.9 \\
\hline CA1 & $\begin{array}{l}2,986,260 \\
(1,727,048)\end{array}$ & $\begin{array}{l}2,215,244 \\
(1,185,499)\end{array}$ & 771,016 & $7,584,266$ & 10.2 & ns & 210.5 & 70.5 \\
\hline CA2 & $\begin{array}{l}919,574 \\
(287,449)\end{array}$ & $\begin{array}{l}889,200 \\
(203,703)\end{array}$ & 30,374 & $1,375,511$ & 2.2 & ns & 8.3 & 9.0 \\
\hline CA3 & $\begin{array}{l}655,428 \\
(255,405)\end{array}$ & $\begin{array}{l}720,055 \\
(201,407)\end{array}$ & 0 & $1,062,288$ & & & & \\
\hline CA4 & $\begin{array}{l}658,923 \\
(467,298)\end{array}$ & $\begin{array}{l}541,710 \\
(202,098)\end{array}$ & 117,213 & $1,105,866$ & 10.6 & ns & 32.0 & 48.6 \\
\hline Subiculum & $\begin{array}{l}1,760,757 \\
(562,251)\end{array}$ & $\begin{array}{l}1,524,200 \\
(385,960)\end{array}$ & 236,557 & $3,049,650$ & 7.8 & ns & 64.6 & 36.7 \\
\hline Amygdala & $\begin{array}{l}5,203,993 \\
(1,311,409)\end{array}$ & $\begin{array}{l}5,340,980 \\
(1,023,388)\end{array}$ & 0 & $6,978,730$ & & & & \\
\hline Thalamus & $\begin{array}{l}12,891,781 \\
(2,374,425)\end{array}$ & $\begin{array}{l}9,635,097 \\
(2,965,348)\end{array}$ & $3,256,684$ & $14,774,176$ & 22.0 & $0.02^{*}$ & 889.1 & 69.0 \\
\hline Substantia nigra & $309,905(65,494)$ & $265,558(44,657)$ & 44,347 & 550,053 & 8.1 & ns & 12.1 & 39.1 \\
\hline$M B C$ & $\begin{array}{l}783,233 \\
(205,770)\end{array}$ & $\begin{array}{l}560,206 \\
(200,686)\end{array}$ & 223,027 & 981,577 & 22.7 & $0.04^{*}$ & 60.9 & 77.7 \\
\hline Caudate n & $\begin{array}{l}27,913,089 \\
(10,600,000)\end{array}$ & $\begin{array}{l}28,785,213 \\
(5,986,303)\end{array}$ & 0 & $41,434,112$ & & & & \\
\hline Purkinje cells & $\begin{array}{l}11,715,680 \\
(2,207,151)\end{array}$ & $\begin{array}{l}9,790,558 \\
(4,117,606)\end{array}$ & $1,925,122$ & $14,247,128$ & 13.5 & ns & 525.6 & 44.9 \\
\hline \multirow[t]{2}{*}{ Dentate $n$} & $520,173(96,537)$ & $\begin{array}{l}473,472 \\
(100,863)\end{array}$ & 46,701 & 510,829 & 9.1 & ns & 12.7 & 24.5 \\
\hline & & & $\begin{array}{l}\text { Total loss: } \\
7,714,105 \\
\text { neurons }\end{array}$ & & $\begin{array}{l}\text { Mean loss: } \\
11.0 \%\end{array}$ & & $\begin{array}{l}\text { Mean loss: } \\
\text { 191.5/d Total } \\
\text { loss: 2,106.0 } \\
\text { /d }\end{array}$ & $\begin{array}{l}\text { Mean loss: 46.1/ } \\
\text { million/d }\end{array}$ \\
\hline
\end{tabular}

${ }^{*}$ Calculated using the 10.04-year (3,663-day) difference in mean age between the groups as the denominator. AD-associated neuronal loss (\%) calculated in all age groups in reference to baseline number of neurons in DS subjects 26-41 years of age with developmental deficit but no or minimal pre-AD pathology

and $22.7 \%$ loss in the 5 th and 6th decades respectively, reflecting structure-specific trajectories of AD neuronal loss in the DS cohort.

The total regional cumulative neuronal loss (\%) in 43- to 72-year-old DS/AD subjects revealed, as was expected for this dementing disorder, the most severe total neuronal loss in the EC (59.4\%) and the second layer of the EC (73.9\%) as well as in all CA sectors, ranging from $70.8 \%$ in $\mathrm{CA} 1$ to $35.4 \%$ in CA2, and $50 \%$ loss in the subiculum. These losses were paralleled by prominent neuronal losses in the dopaminergic ( $\mathrm{SN}$, $51.7 \%$ ) and cholinergic (MBC, $44.2 \%$ ) systems as well as in the amygdala (27.9\%) and thalamus (34.7\%) (Fig. 6).
The general pattern of neuronal loss in three age stages of AD in DS subjects is reflected in an $11.9 \%$ mean neuronal loss in all 14 structures in the 4th decade, a two-fold increase in mean neuronal loss to $28.0 \%$ in the 5 th decade, but an almost 2.7 -fold decrease to $11.0 \%$ in the sixth decade with its prevalence of severe AD. The global relationships between the magnitude of developmental neuronal deficits and AD-associated neuronal loss are characterized by a very similar total developmental neuronal deficit of 40.8 million and an $\mathrm{AD}$-associated total neuronal loss in 43- to 72-year-old DS subjects estimated as 41.6 million (Fig. 6). 
Staging of dynamics of neuronal loss-number of neurons lost per day and normalized rate of neuronal loss per million neurons/day

The index of neuronal loss calculated per million neurons per day is independent of the size of the neuronal population in the examined structure and provides comparable measures of the rate of neuronal loss. The rate of neuronal loss in DS subjects 43-49 years of age is relatively low and varies broadly, from undetectable in the $\mathrm{EC}$ and EC second layer, the amygdala, and MBC to a loss of 64.3 neurons/million/day in the CA1, 58.8 in the $\mathrm{SN}, 62.5$ in the $\mathrm{CN}$, and loss of 54.4 Purkinje cells/million/day (Table 6, Fig. 7). The highest rate of neuronal loss is detected in 51- to 59-year-old DS subjects, with an especially high rate in the EC (145.3), the second layer of the EC (218.3), and the CA, ranging from 138.3 in CA1 to $97.8 / \mathrm{million} /$ day in CA4 (Table 7, Fig. 7). However, the rate of neuronal loss decreases several-fold in 61- to 72-year-old DS subjects (Table 8, Fig. 7).

The global pattern of dynamics of neuronal loss is reflected in an increase in the mean rate of neuronal loss in examined regions from 25.7 neurons/million/ day in the fourth decade to 96.6 neurons/million/day in the fifth decade, but a decrease in the late stage of $\mathrm{AD}$ to 46.1 neurons/million/day in the sixth decade of life of DS subjects. The direct index of total neuronal loss (N/day) in examined structures, declining from 4,318/day in the fourth decade, to 4,278 in the fifth decade and 2,106 in the sixth decade, reflects a diminishing pool of neurons in examined structures and a diminished speed of neuronal loss (Fig. 7).

\section{Staging of neurofibrillary degeneration in DS/AD}

In the pre-AD stage in 26- to 41 -year-old DS subjects, neurons with NFTs were detected in 12 examined structures, but not in the dentate nucleus and Purkinje cells. The mean percentage of NFT-positive neurons in this group was $4.1 \%$, but the percentage of neurons with NFTs was relatively high in the second layer of the EC (28.4\%) and in the amygdala (5.8\%) (Table 9, Fig. 8). The mean percentage of NFT-positive neurons increased to $7.6 \%$ in 43- to 49-year-old DS subjects with mild AD. The result of further enhancement of neurofibrillary degeneration in 51-to 59-year-old DS subjects was a several-fold increase in the percentage of neurons with NFTs to a mean of $29.5 \%$. The most prominent increase of degeneration was
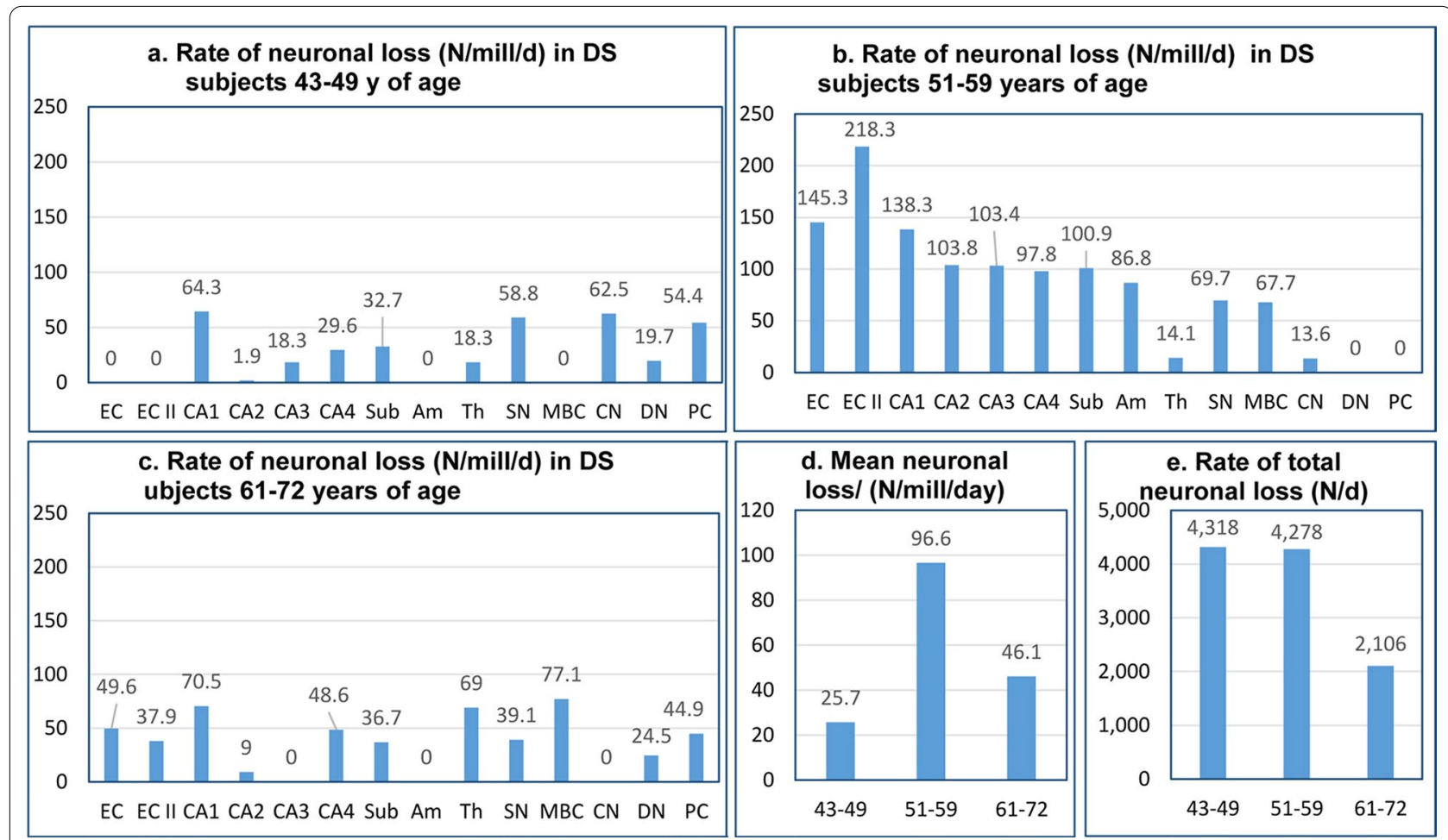

Fig. 7 Rate of neuronal loss. The speed of neuronal loss is defined by the estimated rate of neuronal loss per day and the number of lost neurons per million neurons/day. Graphs a-c illustrate regional differences in the rate of neuronal loss in the fourth, fifth, and sixth decades of life, respectively, of DS subjects. $\mathbf{b}$ and $\mathbf{d}$ reveal the top level of the rate of neuronal loss in the fifth decade. The cumulative rate of neuronal loss (number of lost neurons per day in all examined regions) is similar in the fourth and fifth decades (4,318/day and 4,278/day, respectively) but decreases by half in the sixth decade (2,106/day) (e) 
Table 9 Brain-region and neuron-type specific number and percentage of neurons with NFTs in four DS age groups

\begin{tabular}{|c|c|c|c|c|c|c|c|c|c|c|c|c|}
\hline \multirow[t]{2}{*}{ Structures/ subdivisions } & \multicolumn{3}{|c|}{ DS 26-41y } & \multicolumn{3}{|l|}{ DS 43-49 } & \multicolumn{3}{|l|}{ DS 51-59 } & \multicolumn{3}{|l|}{ DS 61-72 } \\
\hline & Number & Std.dev & $\%$ & Number & Std.dev & $\%$ & Number & Std.dev & $\%$ & Number & Std.dev & $\%$ \\
\hline Entorhinal cortex - all layers & 514,085 & 489,465 & 5.3 & 1268,542 & 831,686 & 11.7 & $2,677,856$ & $1,037,522$ & 47.7 & $2,231,773$ & 579,014 & 51.4 \\
\hline Entorhinal cortex-islands & 146,574 & 162,300 & 28.4 & 256,579 & 109,260 & 42.3 & 179,363 & 75,840 & 93.9 & 156,215 & 67,649 & 93.7 \\
\hline CA1 & 223,781 & 236,938 & 3.5 & 569,738 & 589,164 & 10.0 & $2,194,866$ & $1,311,918$ & 75.3 & $1,466,271$ & 601,308 & 73.8 \\
\hline CA2 & 13,140 & 17,748 & 1.0 & 41,525 & 22,381 & 3.0 & 194,360 & 83,202 & 23.4 & 177,765 & 100,826 & 21.4 \\
\hline CA3 & 15,185 & 17,566 & 2.2 & 25,010 & 22,499 & 2.3 & 177,270 & 71,494 & 30.2 & 182,371 & 106,649 & 27.9 \\
\hline CA4 & 36,758 & 43,532 & 3.8 & 63,735 & 26,396 & 6.3 & 218,396 & 131,984 & 38.8 & 164,995 & 81,514 & 32.8 \\
\hline Subiculum & 47,304 & 54,955 & 1.8 & 92,647 & 50,976 & 3.5 & 522,375 & 276,322 & 29.7 & 468,360 & 153,094 & 30.8 \\
\hline Amygdala & 394,698 & 336,152 & 5.8 & $1,114,323$ & $1,402,649$ & 14.2 & $1,558,170$ & 454,192 & 30.9 & $1,628,256$ & 482,296 & 31.3 \\
\hline Thalamus & 57,382 & 50,262 & 0.4 & $1,456,602$ & $1,055,296$ & 10.9 & $2,069,313$ & 858,102 & 16.0 & $1,813,647$ & 664,388 & 13.5 \\
\hline Substantia nigra & 16,719 & 28,958 & 2.7 & 5,246 & 10,492 & 1.7 & 23,633 & 13,163 & 7.7 & 20,880 & 5,545 & 7.9 \\
\hline $\mathrm{MBC}$ & 19,178 & 33,040 & 1.8 & 31,660 & 24,200 & 3.0 & 132,521 & 68,454 & 18.9 & 98,998 & 81,179 & 17.5 \\
\hline Caudate nucleus & 4,006 & 8,012 & 0.01 & 18,038 & 36,075 & 0.1 & 327,071 & 241,425 & 1.3 & 142,340 & 123,159 & 0.6 \\
\hline Purkinje cells & 0 & 0 & 0 & 0 & 0 & 0 & 0 & 0 & 0 & 0 & 0 & 0 \\
\hline Dentate nucleus & 0 & 0 & 0 & 1,323 & 1,603 & 0.2 & 2,588 & 1,432 & 0.5 & 3,363 & 1,670 & 0.7 \\
\hline Total number; mean \% & $1,488,810$ & & 4.1 & $4,944,968$ & & 8.4 & $10,277,782$ & & 31.9 & $8,555,234$ & & 31.0 \\
\hline
\end{tabular}

detected in the second layer of the EC (94\%), all layers of the EC (48\%), and CA1 (75\%). Approximately $20-30 \%$ of neurons were affected by neurofibrillary degeneration in other segments of the CA, subiculum, amygdala, and MBC. A sign of a plateau of neurofibrillary degeneration was the stabilization of a similar percentage of neurons with NFTs (mean 28.8\%) in DS subjects 61-72 years of age with severe $A D$, but with a very high percentage of neurons with NFTs in the second layer of the EC (94\%), all layers of the EC (51\%), and CA1 (74\%). The total number of neurons with NFTs in all examined structures increased from 1.6 million in 26- to 41-year-old DS subjects in the pre-AD stage to 4.7 million in the fourth decade, and a ceiling level in the fifth decade, with 10.5 million neurons with NFTs. The reduction in the pool of brain neurons and the death of neurons with NFTs result in a decrease in the number of NFTs to 8.5 million in 61to 72-year-old DS subjects.

\section{Staging of $\beta$-amyloidosis in DS/AD}

Amyloidosis shows significant regional differences, but regional patterns of high or low $A \beta$ load are preserved during the entire course of the disease (Table 10, Fig. 9ae). High mean amyloid load in the amygdala, entorhinal cortex, and subiculum $(10.8 \%, 9.5 \%$, and $7.0 \%$, respectively) in the pre-AD stage appears to be a predictor of high $(13.5 \%, 12.2 \%$, and $11.0 \%$, respectively) mean amyloid load during 30 years of AD. The mean amyloid load increases from $2.8 \%$ in pre-AD to $6.1 \%, 7.1 \%$, and $6.5 \%$ in the fourth, fifth, and sixth decades of the DS/AD subject's life (Fig. 9f). Direct estimates of amyloid deposits $\left(\mathrm{mm}^{3}\right)$ reveal that the transition from the pre-AD stage (26-41 y of age) $\left(286 \mathrm{~mm}^{3}\right)$ to the fourth decade $(43-49$ y) results in an almost five-fold increase of amyloid volume to 1,408 $\mathrm{mm}^{3}$. The decrease of total volume of amyloid- $\beta$ deposits in the fifth and sixth decades to $1,284 \mathrm{~mm}^{3}$ and $974 \mathrm{~mm}^{3}$ (Fig. 9g) respectively reflects the consequences of earlyonset $\mathrm{AD}$-associated loss of neurons and exhaustion of this main source of $A \beta$, resulting in a decline of the amyloid pool in plaques and diffuse deposits.

\section{Correlations between neuron number and structure volume decline and the number and percentage of neurons with NFTs}

Strong correlations in almost all examined structures between neuron number and the percentage of neurons with NFTs reflect the critical role of neurofibrillary degeneration in $\mathrm{AD}$ neuronal loss and functional decline. Correlations between declining neuron number and the volumes of all examined structures mirror the leading role of neurofibrillary degeneration and neuronal loss in brain atrophy (Table 11). The pattern detected is consistent with clinicopathological staging of the dynamics of pathological changes with the following ceiling levels: total volume loss $\left(2,953 \mathrm{~mm}^{3}\right)$ in the fourth decade, mean percentage of volume loss (15.7\%) in the fifth decade, total number of lost neurons (20.4 million) in the fourth decade, mean percentage of neuronal loss $(28.0 \%)$ in the fifth decade, mean rate of neuronal loss (96.6 million/day) in the fifth decade, top level of the rate of neuronal loss in the fourth/fifth 

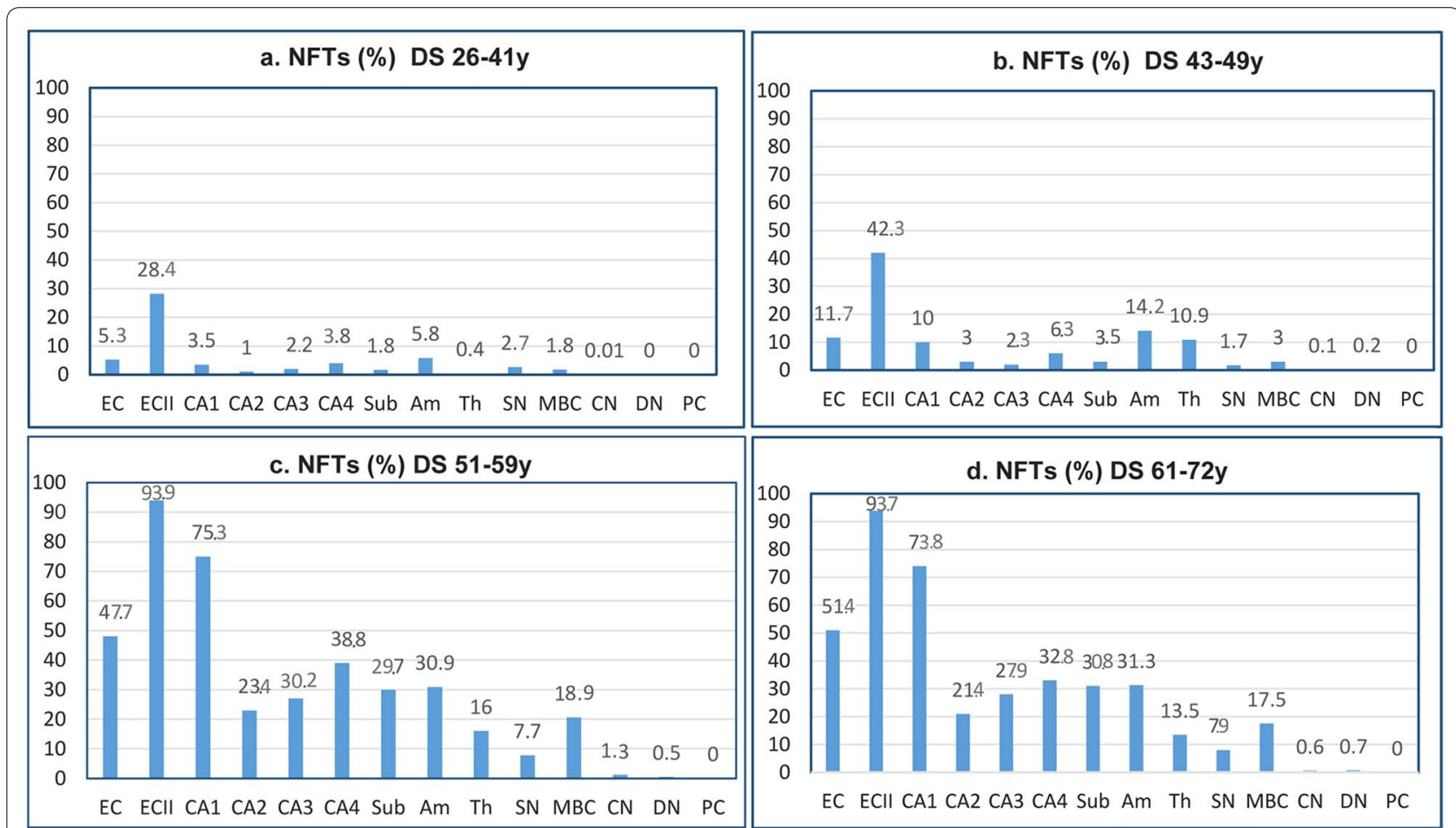

EC ECII CA1 CA2 CA3 CA4 Sub Am Th SN MBC CN DN PC
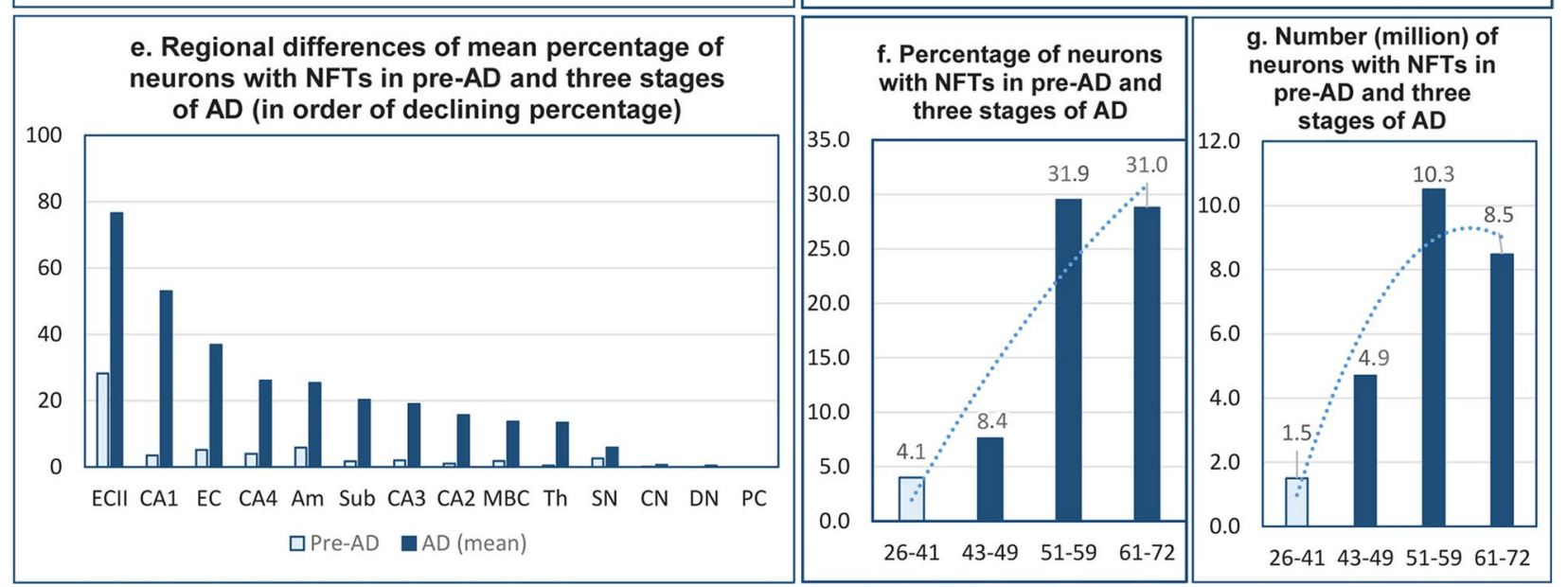

Fig. 8 Neurofibrillary degeneration. Graphs a-e illustrate regional differences in the percentage of neurons with NFTs and the progression of neurofibrillary degeneration from the incipient stage in pre-AD (26- to 41-year-old DS subjects) to three stages of AD in the fourth, fifth, and sixth decades. Fig. e shows the ratio between the percentage of neurons with NFTs in pre-AD and in AD and the gradient of susceptibility of neurons, with the highest in the entorhinal cortex, cornu Ammonis, subiculum, and amygdala; lower in the MBC, thalamus, and substantia nigra; and marginal in the caudate and dentate nuclei. The general pattern is illustrated in fig. $\mathbf{f}$ and $\mathbf{g}$, showing a plateau of the percentage of neurons with NFTs in the fifth and sixth decades. Decrease of the number of neurons with NFTs from 10.3 million in the fifth decade to 8.5 million in the sixth decade is evidence of the death and removal of neurons with NFTs

decades (4,318/day and 4,278/day, respectively), highest level of the percentage of neurons with NFTs in the fifth decade $(29.5 \% / 28.8 \%$, respectively), highest level of the number of neurons with NFTs (10.5 million) in the fifth decade, highest level of mean amyloid load (7.1\%) in the fifth decade, and highest level of amyloid volume $(1,408 \mathrm{~mm} 3)$ in the fourth decade. 
Table 10 Brain region-specific amyloid volume $\left(\mathrm{mm}^{3}\right)$ and amyloid load (\%) in four DS age groups

\begin{tabular}{|c|c|c|c|c|c|c|c|c|}
\hline \multirow[t]{2}{*}{ Structures/ subdivisions } & \multicolumn{2}{|c|}{ DS 26-41 y } & \multicolumn{2}{|c|}{ DS $43-49 y$} & \multicolumn{2}{|c|}{ DS 51-59y } & \multicolumn{2}{|c|}{ DS 61-72 y } \\
\hline & Volume & Load & Volume & Load & Volume & Load & Volume & Load \\
\hline Entorhinal cortex-all layers & 58.2 & 9.5 & 77.7 & 12.7 & 56.4 & 13.1 & 38.8 & 10.7 \\
\hline $\mathrm{CA} 1$ & 1.3 & 0.4 & 10.3 & 4.0 & 18.4 & 9.0 & 10.4 & 7.0 \\
\hline CA2 & 0.1 & 0.2 & 0.0 & 0.0 & 1.4 & 3.0 & 0.4 & 1.4 \\
\hline CA3 & 0.1 & 0.2 & 0.4 & 1.3 & 1.6 & 5.0 & 0.7 & 2.0 \\
\hline CA4 & 1.3 & 2.0 & 2.2 & 4.0 & 5.6 & 8.0 & 3.3 & 6.0 \\
\hline Subiculum & 10.9 & 7.0 & 16.9 & 12.0 & 10.0 & 10.0 & 8.6 & 11.0 \\
\hline Amygdala & 45.4 & 10.8 & 61.6 & 14.2 & 54.3 & 13.9 & 40.4 & 12.5 \\
\hline Thalamus & 36.0 & 1.2 & 74.6 & 2.9 & 74.2 & 3.0 & 80.6 & 4.0 \\
\hline Substantia nigra & 0.0 & 0.0 & 0.2 & 0.2 & 0.8 & 0.9 & 1.0 & 1.4 \\
\hline$M B C$ & 2.3 & 1.5 & 9.4 & 5.5 & 7.3 & 5.4 & 14.4 & 6.5 \\
\hline Caudate nucleus & 81.8 & 3.6 & 189.9 & 11.2 & 140.0 & 9.5 & 222.7 & 15.0 \\
\hline Cerebellar cortex molecular layer & 49.1 & 0.5 & 965.5 & 12.0 & 914.5 & 11.5 & 561.3 & 7.0 \\
\hline Dentate nucleus & 0.0 & 0.0 & 0.0 & 0.0 & 0.0 & 0.0 & 0.0 & 0.0 \\
\hline Total (sum) Vol and mean load & 286.5 & 2.8 & $1,408.6$ & 6.1 & $1,284.5$ & 7.1 & 974.3 & 6.5 \\
\hline
\end{tabular}

Enhancement of amyloid angiopathy in the EC, CA1, subiculum, and molecular layer of the cerebellar cortex in the sixth decade of life of DS/AD subjects

Amyloid angiopathy was detected in all four regions in the wall of capillaries as well as in the tunica media in the wall of arterioles and small-caliber arteries in all examined DS subjects. The numerical density of amyloidpositive vessels ranged from $3.19 / \mathrm{mm}^{2}$ in the EC to $6.88 /$ $\mathrm{mm}^{2}$ in the molecular layer of the cerebellar cortex in 61- to 72-year-old DS subjects. The study revealed ageassociated advancement of amyloid angiopathy reflected in the higher number of positive vessels in 61- to 72-yearold DS/AD subjects in comparison to 41- to 59-year-old DS/AD subjects by $30.8 \%$ in the EC, $21.4 \%$ in CA1, $49.9 \%$ in the subiculum, and $21.0 \%$ in the molecular layer of the cerebellar cortex.

\section{Prevalence and severity of Lewy body degeneration in the amygdala in DS/AD subjects}

The immunostaining with mouse mAb 4B12 detecting $\alpha$-synuclein in Lewy bodies in neurons in the amygdala in 12 of $22(54.5 \%)$ DS subjects $41-59$ years of age and in six of eight examined subjects $61-72$ years of age (75\%) reflects the age-associated increase in the prevalence of $\alpha$-synucleinopathy in DS. In the amygdala of DS subjects, the estimated numerical density of Lewy bodies was $761 / \mathrm{mm}^{3}$, and the average total number per case was 290,647 , with $4.6 \%$ of neurons being Lewy body positive. However, the decline in the number of neurons with Lewy bodies from $861 / \mathrm{mm}^{3}$ to $575 / \mathrm{mm}^{3}$ $(-33 \%)$, and in the total number of neurons with Lewy bodies from 337,000 to 201,000 in 61- to 72-year-old DS subjects indicates that $\alpha$-synucleinopathy results in neuronal death in DS/AD subjects and in removal of $39.9 \%$ of affected neurons in the amygdala.

\section{Low prevalence of TDP-43 neurodegeneration} and percentage of affected neurons in DS cohort

Immunostaining with rabbit polyclonal phosphorylation-independent anti-TDP-43 antibody 10,782-1-AP revealed cytoplasmic inclusions of aggregated TDP-43 protein in the amygdala of only three of 33 DS subjects (9.0\%), who died at 59, 61, and 65 years of age. The percentage of neurons with cytoplasmic TDP-43-positive inclusions was $0.8,0.4$, and 7.9, respectively, and the estimated numerical density of positive neurons was $88 /$ $\mathrm{mm}^{3}, 53 / \mathrm{mm}^{3}$, and $1,452 / \mathrm{mm}^{3}$ ), respectively.

\section{The pattern of major age-associated pathological processes in DS/AD cohort}

Figure 10 provides overview of onset of neurofibrillary degeneration in 26-41-year-old DS subjects, two decades of progress of neurodegeneration culminating at an age of around 60 years and decline in the sixth decade. Neurofibrillary degeneration results in three decades of neuronal loss, atrophy of examined structures and functional deterioration including dementia. The increase of amyloid load most prominent in 26-41-year-old individuals is less intense in the next three decades and decreases in the 6th decade in response to exhaustion of $A \beta$ supply by severely downsized neuronal population. 

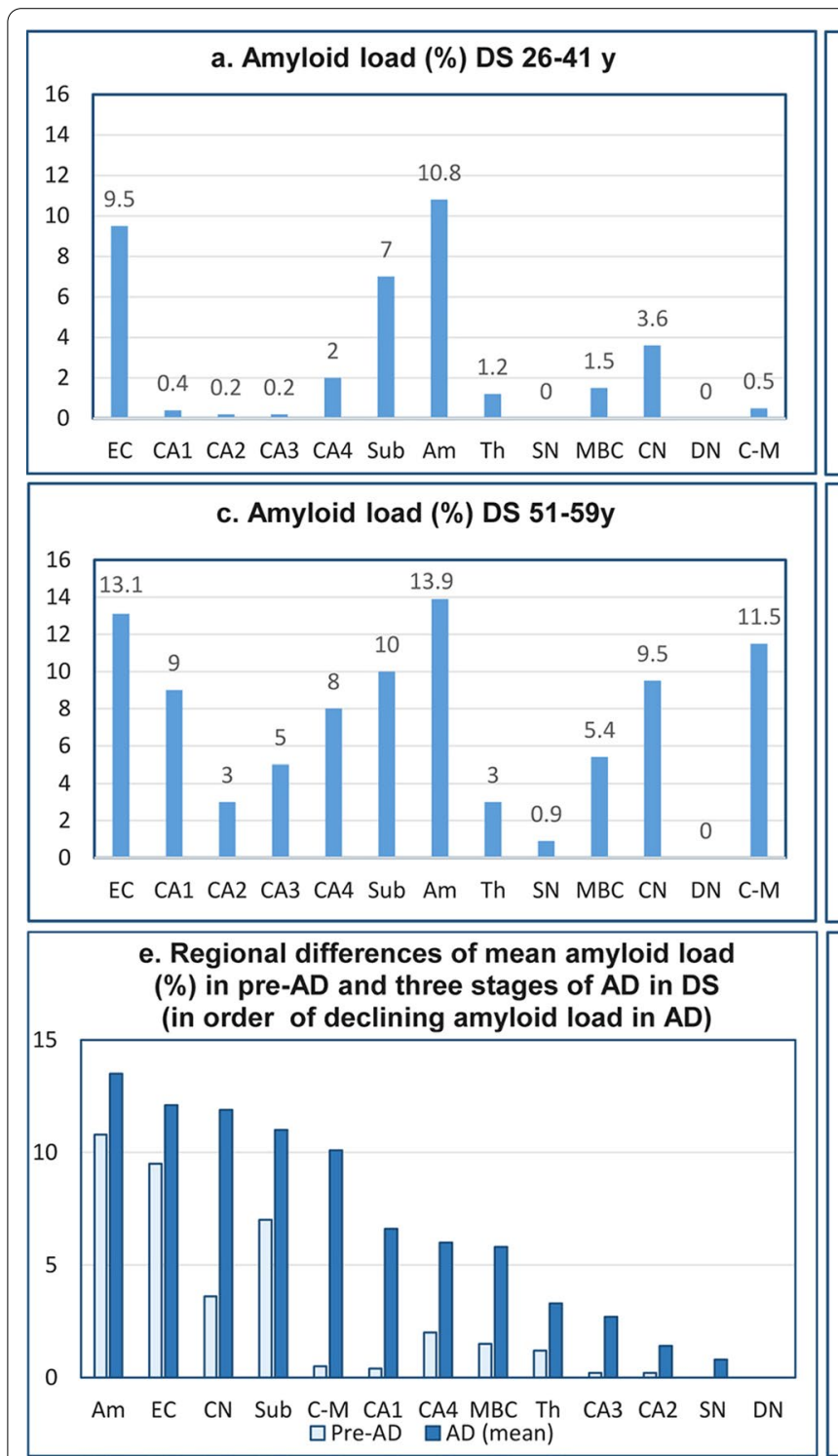

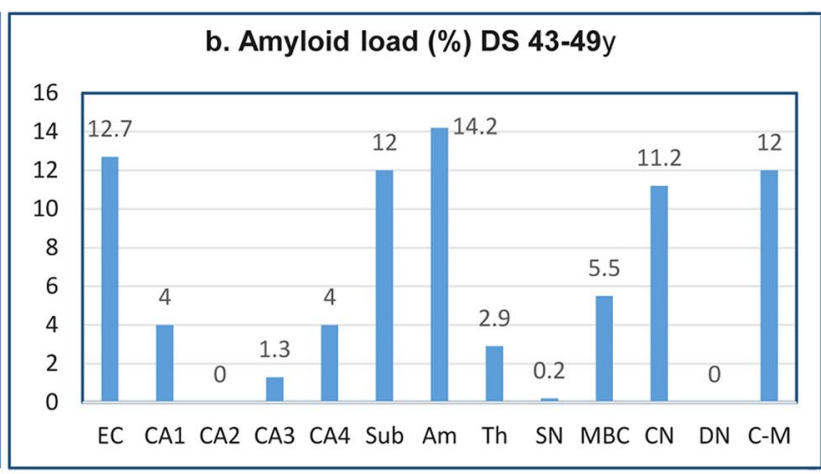

d. Amyloid load (\%) DS 61-72y
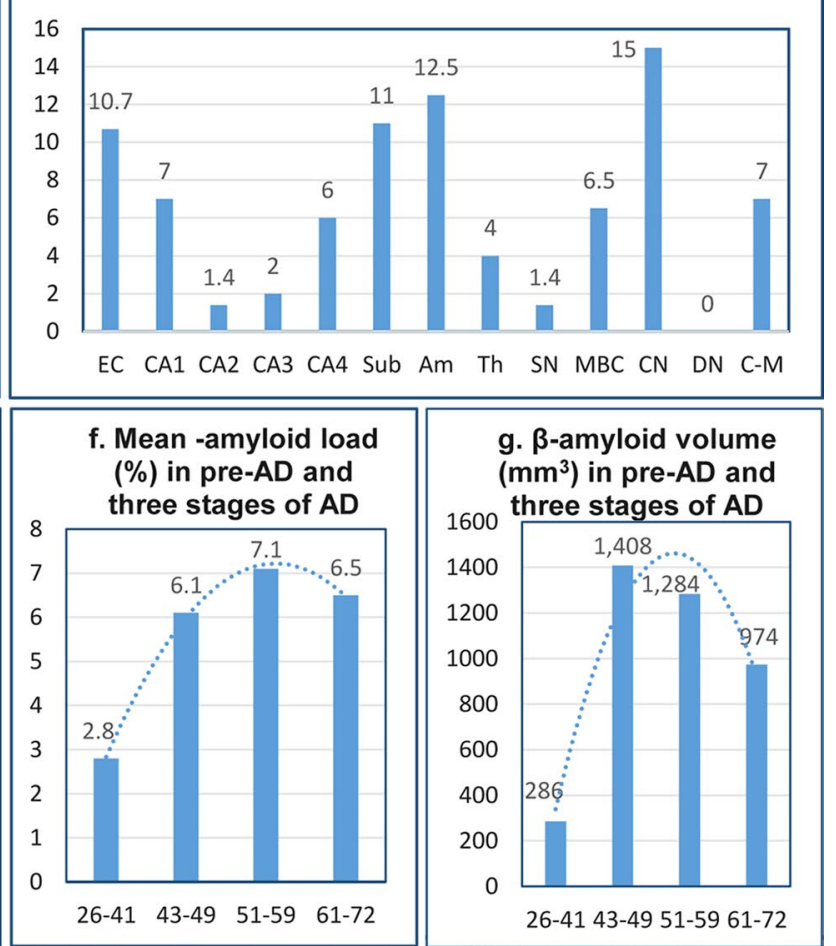

Fig. 9 Amyloid load (\%). Fig. a shows the onset of amyloidosis in pre-AD with marked amyloid load in the entorhinal cortex, amygdala, and subiculum, and much less in the CN, CA4, MBC, and thalamus. Amyloid load increases in a region-specific range and stabilizes to comparable levels in the fourth, fifth, and sixth decades (b-d, respectively). Graph e illustrates grading of regional susceptibility to $\beta$-amyloidosis and shows that the pattern in pre-AD predicts severity of regional amyloidosis in next decades. Fig. $\mathbf{f}$ and $\mathbf{g}$ show a global pattern of onset and progression of amyloidosis in pre-AD and in the fourth and fifth decades but a decrease of amyloid load (\%) and amyloid volume $\left(\mathrm{mm}^{3}\right)$ in the sixth decade of life of DS subjects

\section{Discussion}

Trisomy 21-associated structural developmental deficits in the brain of DS subjects-the baseline for estimation of early-onset AD pathology in DS

This and other studies demonstrate that the reduced size of brain structures in adults with DS is a combined effect of developmental deficits and acquired AD pathology [16] and indicate that estimation of ADassociated neuronal loss in older DS subjects must be calculated as the percentage of the number of neurons in AD pathology-free young DS subjects [48]. In DS, neurodevelopmental pathologies, including deficits of neurogenesis, synaptogenesis, and lamination, contribute to the reduced size of brain structures and the reduced number of neurons and synapses [72, 103, 106]. This study of 14 brain regions characterized ADrelated topography and severity of volume loss and loss of neurons in the context of trisomy 21-related 
Table 11 Correlations in DS cohort

\begin{tabular}{|c|c|c|c|}
\hline \multirow[t]{2}{*}{ Structure } & \multicolumn{3}{|c|}{ Correlation with neuron number of: } \\
\hline & Structure volume & NFT number & NFT\% \\
\hline $\begin{array}{l}\text { Entorhinal cortex-all } \\
\text { layers }\end{array}$ & $0.89^{* * *}$ & -0.09 & $-0.74^{* * *}$ \\
\hline $\begin{array}{l}\text { Entorhinal cortex - } \\
\text { islands }\end{array}$ & $0.93^{* * *}$ & 0.25 & $-0.89^{* * *}$ \\
\hline CA1 & $0.92^{* * *}$ & -0.01 & $-0.76^{* * *}$ \\
\hline CA2 & $0.79^{* * *}$ & $-0.44^{*}$ & $-0.66^{* * *}$ \\
\hline CA3 & $0.80^{* * *}$ & -0.24 & $-0.61^{* * *}$ \\
\hline CA4 & $0.41^{*}$ & -0.29 & $-0.62^{* * *}$ \\
\hline Subiculum & $0.92^{* * *}$ & -0.17 & $-0.53^{* * *}$ \\
\hline Amygdala & $0.60^{* * *}$ & 0.04 & $-0.46^{* * *}$ \\
\hline Thalamus & $0.53^{* * *}$ & -0.31 & -0.37 \\
\hline Substantia nigra & $0.85^{* * *}$ & -0.06 & $-0.41^{*}$ \\
\hline $\begin{array}{l}\text { Magnocellular basal } \\
\text { complex }\end{array}$ & $0.85^{* * *}$ & -0.16 & $-0.50^{* *}$ \\
\hline $\mathrm{CN}$ & $0.87^{* * *}$ & -0.20 & $-0.38^{*}$ \\
\hline DN & 0.22 & 0.28 & -0.15 \\
\hline
\end{tabular}

${ }^{*} p<0.05 ;{ }^{* *} p<0.01 ;{ }^{* * *} p<0.001$

topography and severity of developmental brain volume and number of neuron deficits.

Region-specific developmental brain volume deficits in DS This study of DS subjects' brains in the pre-AD stage of life (26-41 years of age) revealed a $12.8 \%$ mean developmental volume deficit in 14 structures and regional volume deficits by $27.2 \%$ in CA1, $36.2 \%$ in CA4, $17 \%$ in ECII, $14.9 \%$ in the subiculum, and $7.0 \%$ in the amygdala. A similar range of developmental changes was detected in the cerebellum, with a $31.6 \%$ deficit in the volume of the molecular layer of the cerebellar cortex and a $23.1 \%$ volume deficit in the dentate nucleus. Deficits distinguished in 11 structures and the absence of developmental deficits in the CA2, substantia nigra, and $M B C$ reflect regional differences in defective brain development and implicate their different contributions to functional developmental deficits in individuals with DS.

These observations are consistent with results of MRI studies of the brains of fetuses [60,82], infants and toddlers [78], and teenagers [63] with trisomy 21. Fetal and neonatal MRI assessment of developmental brain alterations indicates that brain pathology in DS originates in utero and continues over the lifespan. Fetuses with DS had decreased cerebellar hemispheric $(p<0.0001)$, whole cerebellum $(p=0.043)$, cortical plate $(p=0.033)$, and subcortical parenchymal volume $(p=0.010)$ compared to control fetuses. Such differences began at around GW 28 and increased during gestation [82]. The reduced cerebellar volume detected in the second trimester and the significant reduction of cortical volume evident during the third trimester are considered the substrate for neurocognitive impairment [60]. MRI-based studies show reflections of fetal pathology in infants and toddlers as the deficit of cerebellar gray matter [78] as well as smaller brain, cerebellum, and hippocampus volume in 5- to 23-year-old DS subjects [62, 63]. According to Pinter et al. [62], the stable nature of these abnormalities may reflect their contribution to the cognitive and functional deficits in DS subjects.

\section{Region-specific developmental neuronal deficits in DS}

Widespread hypoplasia in the brain of 16- to 21-week-old fetuses with karyotypically proven trisomy 21 is associated with deficits of brain structure volume and number of neurons, including deficits of $39 \%$ in the total number of granule cells in the dentate gyrus, of $35 \%$ in neurons in the hippocampal pyramidal layer, of $38 \%$ in neurons in the presubiculum lamina principalis interna, and of $32 \%$ in neurons in the lamina principalis externa. In the EC, neuronal deficit ranges between $32 \%$ in the lamina principalis interna and $37 \%$ in the lamina principalis externa [24]. Comparison by Larsen et al. [41] of the total cell number in the major fetal brain regions, including the cortical plate, the subplate, and the intermediate and ventricular zones, revealed that the total cell number in 19-week-old fetuses with trisomy 21 ( 6.85 billion) is $34 \%$ less than the total cell number in age-matched control fetuses (10.4 billion). The reduced neuron number detected in DS fetuses and children [11, $24,41]$ indicates that trisomy-related developmental abnormalities of neurogenesis are a major contributor to multiregional hypoplasia in the brains of DS individuals and to functional deficits including intellectual deficits [41].

(See figure on next page.)

Fig. 10 Overview of the staging of AD-associated changes of examined structures volume $\left(\mathrm{mm}^{3}\right)$, number of neurons and NFTs (million), and amyloid load (\%) in the entorhinal cortex (EC), cornu Ammonis sector 1 (CA1), subiculum (Sub), amygdala (Amyg), and thalamus (Th) in DS subjects 26-41, 43-49, 51-59, and 61-72 years of age. Graphs illustrate structure-specific staging of brain structures volume and neuronal number decline paralleled with the growth of the number of neurons with NFTs and increase of amyloid load associated with functional decline, including onset and progression of dementia in the fifth/sixth decades of life of subjects with trisomy 21 . The upper and lower boundaries of the box represent interquartile range (IQR). The mean value is marked with the horizontal line within the box. The "whiskers" mark the maximal and minimal values unless any data point lies more than 1.5 times the IQR above the 75 th percentile or below the 25 th percentile. Outliers are marked with dots 


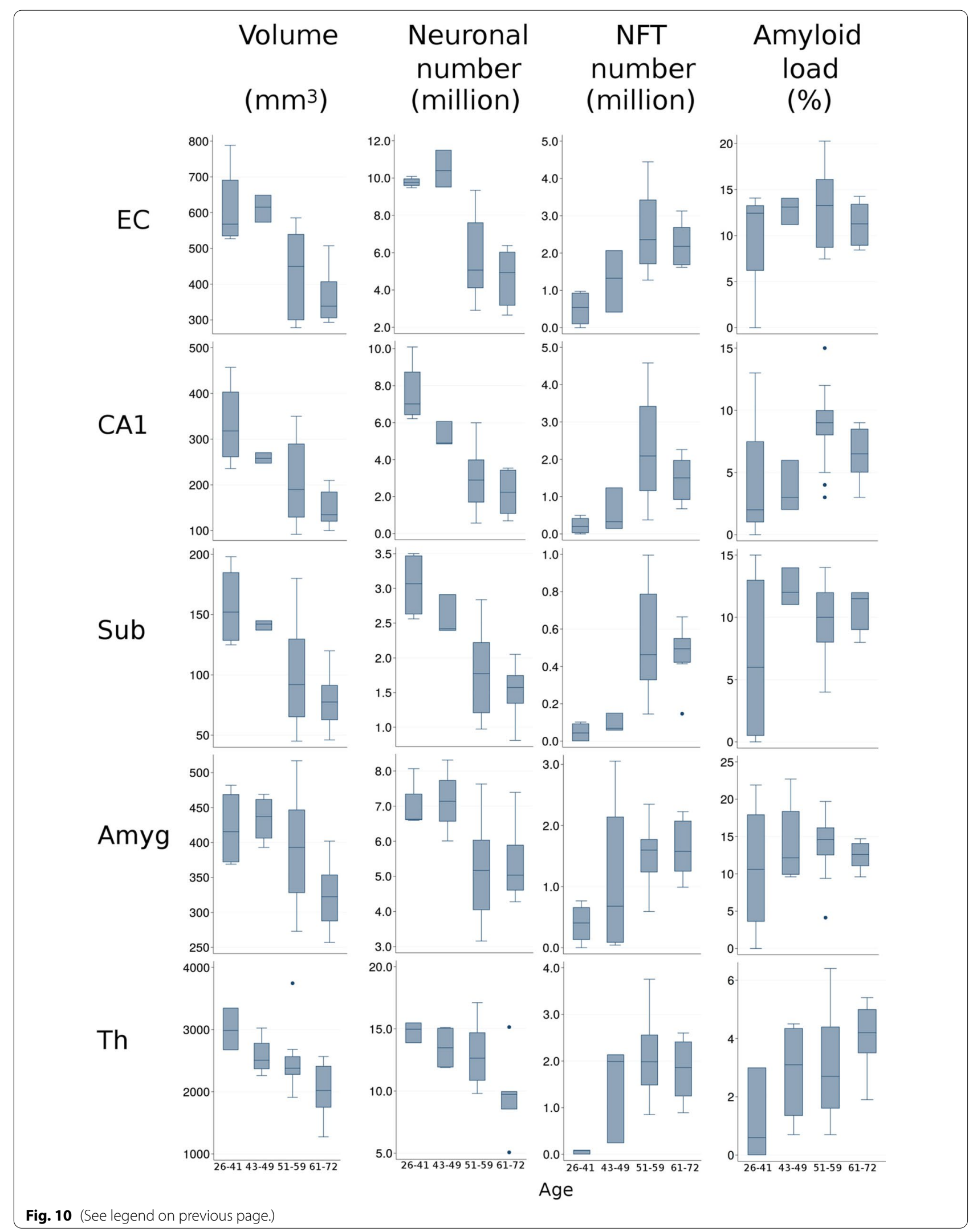


Comparable magnitude of regional developmental neuronal deficits in pre-AD DS subjects and magnitude of regional losses of neuronal reserve in aging: the baseline for onset of AD pathology in DS and in SAD

The baseline for EOAD in subjects with trisomy 21 and DS is defined by brain region-specific neuronal developmental deficits and enhanced apoptotic death [11, 24], which are reflected in developmental deficits of $18.4 \%$ of neurons in the EC, $37.7 \%$ in the second layer of the EC, $38.6 \%$ in the CA1, $50.8 \%$ in the amygdala, $52.5 \%$ in the thalamus, and $66.5 \%$ in the dentate nucleus, and a $34.8 \%$ deficit of Purkinje cells detected in this study. This pattern of developmental region-specific volume and neuronal deficits supports the concept of Annus et al. [3] that the DS brain is not simply a downscaled model of the typically developed brain but is a trisomy-specific product of distinct types, topography, and severity of developmental changes resulting in disproportions between differently deficient regions and loss of structural and functional integrity.

In a nondemented control cohort, the baseline for LOAD is defined by a loss of neurons without signs of functional decline (neuronal reserve). This loss was determined in neurologically typical subjects $25-102$ years of age to be an age-associated loss of $33.3 \%$ of neurons in the EC, $54 \%$ in the second layer of the EC, $28.5 \%$ in the CA1, $45.8 \%$ in the amygdala, $40.5 \%$ in the thalamus, and $40.1 \%$ in the dentate nucleus as well as a $48.5 \%$ loss of Purkinje cells [93]. Age-associated loss of neuronal reserve and remodeling of neuronal networks might be considered the baseline for estimation and staging of an almost 20-year-long process of brain-region-specific $\mathrm{AD}$ neurodegeneration and neuronal loss resulting in the onset and progression of $\mathrm{AD}$ dementia.

Despite topographic and numerical similarities, two fundamentally different processes reflecting abnormal brain development in trisomic DS subjects and ageassociated brain remodeling leading to loss of neuronal reserve in the control cohort independently lower the threshold of onset of symptomatic AD pathology and functional decline with dementia in EOAD in the DS cohort and dementia in LOAD in the general population. The magnitude of these changes is reflected in the neuronal deficit of 40.8 million in 14 examined structures in 26- to 41-year-old DS subjects and a very similar ADassociated 41.6 million total loss of neurons contributing to functional decline including dementia in 43- to 72-year-old DS/AD subjects.

\section{Correlation between age as well as stage of dementia and decline of neuron number in DS/AD}

The study shows that the effect of trisomy 21 is early onset of $\mathrm{AD}$ pathology in the DS cohort, strong correlations between age and decline of the number of neurons in the entorhinal cortex, sectors of the cornu Ammonis, amygdala, thalamus, substantia nigra, magnocellular basal complex, associated with early onset of dementia and strong correlation between stage of dementia and $\mathrm{AD}$ pathology including reduction of the number of neurons and examined structure volume. Very strong correlations between both age and stage of dementia and structural changes detected in the examined cohort are consistent with a $23 \%$ prevalence of dementia at age of 50 years, $45 \%$ at age 55 years, and $88 \%$ or more at 65 years $[53,64,108]$ and the results of Ballard et al. [5] showing the prevalence of progressive cognitive decline in $55 \%$ of DS patients $40-49$ years and $77 \%$ in patients $60-69$ years of age. Detection of correlations between structural changes and both age and stage of dementia integrates three components of AD pathology in DS and suggests that successful preventive treatment before the age of 50 may disrupt/ block this highly predictable cascade of pathology including neuronal loss and loss of function. In contrast to the genetically regulated, highly predictable age of onset and progression of the cascade of AD structural and functional changes in DS, the broad range of age of onset of $\mathrm{AD}$ pathology and dementia in sporadic $\mathrm{AD}$ [7] results in a lack of correlation between age and severity of $\mathrm{AD}$ pathology in LOAD [92].

\section{Different dynamics of volume and neuronal loss in sporadic LOAD and EOAD in DS cohort}

Estimates of AD-associated mean volume losses show a significantly different pattern in these two cohorts, with an increase in mean volume loss in LOAD FAST 3-4, $5-6$, and 7 from $22.2 \%$ to $28.3 \%$ and $43.6 \%$, respectively, whereas mean volume losses in EOAD in developmentally deficient DS brains were less and were relatively stable in the age groups of 43- to 49-, 51- to 59-, and 61- to 72 -year-old DS subjects, with $12.7 \%, 15.7 \%$, and $10.1 \%$ loss, respectively.

The mean rate of neuronal loss (mean number of neurons lost per million neurons/day) shows another striking difference in stage-specific dynamics of $A D$ pathology in these two cohorts, with moderate neuronal loss in 43to 49 -year-old DS subjects (25.7/million/day) but more than a six-fold higher rate of neuronal loss (159 neurons/ million/day) in FAST 3-4 in SAD, and a ceiling level of neuronal loss (96.6/million/day) in 51- to 59-year-old DS subjects, but a 3.4 times higher loss (332/million/day) in corresponding FAST 5-6 in sporadic AD. However, the decrease in the rate of neuronal loss to a floor level (46.1/ million/day) in 61- to 72-year-old DS subjects was relatively similar (64/million/day) to the floor level in FAST 7 in the SAD cohort. 
Our previous study of a LOAD cohort revealed that the mean percentage of neuronal loss decreases from a ceiling level of $31.0 \%$ in $\mathrm{MCI} / \mathrm{mild} \mathrm{AD}$ (FAST 3-4) to $15.5 \%$ in moderate/moderately severe AD (FAST 5-6), and to $13.8 \%$ in severe AD (FAST 7) [94], whereas in this study of EOAD, in the DS cohort, the mean neuronal loss in three corresponding age groups is partly different, with a $11.9 \%$ loss in the fourth decade, an increase to a ceiling level of $28.0 \%$ in the fifth decade, and a decline to $11.0 \%$ in the sixth decade of life of DS subjects. Lower overall neuronal loss in older DS subjects than in subjects with advanced SAD was also reported by Mann et al. [48], and the difference was interpreted as related to a developmentally lower number of neurons in young DS subjects than in age-matched control individuals.

\section{Mechanisms of neuronal loss in DS cohort}

Staging of progression of neurofibrillary degeneration revealed a comparable increase in the percentage of neurons with NFTs in each of three FAST stages in LOAD, from $13.0 \%$ to $24.0 \%$ and $31.0 \%$ [94], and a similar increase in three age groups of the DS/AD cohort, with an increase from $7.6 \%$ to $29.5 \%$ and $28.8 \%$. This and other studies [6] reveal that late-life cognitive decline in $\mathrm{AD}$ is driven by a variety of age-related pathologies and suggest that interpretation of neuronal loss in the DS/AD cohort requires consideration of the role of neurofibrillary degeneration as well as other proteinopathies including $\alpha$-synucleinopathy with Lewy bodies, TDP43 protein aggregation, $\beta$-amyloidosis, and amyloid angiopathy. This broader range of data may be helpful in the design of multi-target treatments and of the timing of treatments matching the clinicopathological staging of $\mathrm{AD}$ and $\mathrm{DS} /$ AD that can disrupt efficiently the chain of synergistic interactions leading to escalation of mutually related pathomechanisms, neuronal loss, and functional decline including dementia.

\section{Low prevalence and limited percentage of neurons with TDP-43-positive cytoplasmic inclusions in DS/AD subjects}

To evaluate the potential contribution of other proteinopathies to neuronal degeneration and loss, as well as the loss of function in the DS cohort, the prevalence (number and percentage of cases with TDP-43 degeneration) and the severity of this degeneration (percentage of neurons with intracellular TDP-43-positive inclusions) were determined in the amygdala. Hyperphosphorylated transactive response DNA-binding protein 43 (TDP-43) is a nuclear ribonucleo-protein involved in protein processing and exon splicing $[46,89]$. In pathological conditions including AD and limbic-predominant age-related TDP-43 encephalopathy (LATE), abnormally phosphorylated TDP-43 is aggregated in the cell nucleus and in multiple cytoplasmic inclusions. In SAD and DS/ $\mathrm{AD}$, the most affected are neurons in the amygdala, adjacent EC, and hippocampus (dentate gyrus) [4, 46, 58]. TDP-43 neurodegeneration extended from the amygdala to other brain structures is frequently associated with increased clinical expression of AD dementia [32, 35] and is considered an integral component of at least some forms of $\mathrm{AD}$ [17].

The low prevalence of TDP-43 degeneration-14\% [14], (8.9\% [15], and 9\%-detected in this study distinguishes subjects with DS from four populations with sporadic AD, with 23\% [1], 26\% [87], 58\% [38], and 56\% [4] positive cases. Our clinicopathological staging of sAD revealed TDP-43 degeneration in only 1 of $11 \mathrm{AD}$ cases diagnosed with early stages of AD (FAST 3-5), but the prevalence increased to $68.7 \%$ in moderately severe and severe AD (FAST 6-7) [94]. The absence of TDP-43 pathology in a substantial percentage of AD cases $[1,85]$ is considered an indication that TDP-43 neurodegeneration is not essential for developing $\mathrm{AD}[85,86]$. However, TDP-43 pathology still may modulate AD pathology and affect the clinical course of disease $[8,33,59]$. The low prevalence of TDP-43 pathology in the examined DS/ AD cohort and other DS cohorts [15, 46] suggests that TDP-43 is not essential for the development of AD in DS subjects and has a limited contribution to the neuronal degeneration/loss and functional decline in DS/AD.

\section{Prevalence of a-synucleinopathy and contribution of Lewy bodies to neuronal death in DS/AD subjects}

Lewy bodies were reported in $63 \%$ of early-onset familial AD cases with known mutations in presenilin or amyloid precursor protein [44]. Estimates of the prevalence of Lewy bodies in DS ranged from one of 12 neuropathologically examined DS cases with Alzheimer-type pathology [39], and in two of 23 people with DS in a study employing antibodies to ubiquitin [68]. In the examined cohort, immunostaining with antibody 4B12 revealed $\alpha$-synuclein-positive Lewy bodies in neurons in the amygdala in $54.5 \%$ of DS/AD subjects $41-59$ years of age. The increase in prevalence of Lewy bodies in the amygdala to $75 \%$ of DS subjects $61-72$ years of age is consistent with the study by Lippa et al. [45] showing increase with age of the prevalence of $\alpha$-synucleinopathy in DS subjects. However, decrease with age in the number of neurons with Lewy bodies from $861 / \mathrm{mm}^{3}$ to $575 / \mathrm{mm}^{3}$ $(-33 \%)$, and decrease of the total number of neurons with Lewy bodies from 337,000 to 201,000 indicates a loss of $39.9 \%$ of neurons with Lewy bodies in $75 \%$ of DS subjects who developed $\alpha$-synucleinopathy. Decline in the percentage of neurons with NFTs from $5.3 \%$ in the fourth-fifth decades to $3.3 \%$ in the sixth decade $(-38 \%)$ 
and 39.9\% loss of neurons with Lewy bodies suggests some contribution of $\alpha$-synucleinopathy to neuronal death in DS subjects.

\section{Unique pattern of $\beta$-amyloidosis in DS}

In the examined DS cohort, $\beta$-amyloidosis was absent in a 26-year-old subject, however, amyloidosis reached final phase 5 in a 28 -year-old subject and progressed to Thal phase 5 in all subjects forty or more years of age. A similar pattern of Thal staging of amyloidosis in the DS cohort was reported by Davidson et al. [15], showing phase 1 in 13- and 27-year-old DS subjects, a prevalence of phase 5 in 36- to 47-year-old subjects, and the presence of phase 5 in all DS subjects 51 years of age and older.

The pre-AD stage in subjects $26-41$ years of age is characterized by $\beta$-amyloidosis with a $2.8 \%$ amyloid load. Consistent with expectations, the amyloid load in DS subjects, with a third copy of the APP gene, is approximately 2-3 times greater in DS subjects in the 43-49, $51-59$, and $61-72$ years of age groups $(6.1 \%, 7.1 \%$, and $6.5 \%$, respectively) than in subjects with LOAD FAST $3-4,5-6$, and 7 (2.1\%, 3.8\%. and 3.6\%, respectively) [94]. Conclusions of this study of brain $\beta$-amyloidosis and neurofibrillary degeneration are consistent with Perez et al. [61] observation that in DS despite the early onset and severe brain $\beta$-amyloidosis, neurofibrillary degeneration is more closely linked to neuronal loss, functional decline and dementia.

\section{Diffuse and fibrillar amyloidosis in DS}

Brain $\beta$-amyloidosis without signs of clinical functional deterioration, reported in some children with DS [43] and in almost all DS subjects 30 years of age and older [100], is characterized by the presence of diffuse nonfibrillar amorphous plaques free of degenerated neuronal processes [101]. The critical change in the pattern of $\beta$-amyloidosis and clinical course of $\mathrm{AD}$ occurs at the end of the third decade of life of DS subjects, marked by the onset and fast topographic expansion of fibrillar $\beta$-amyloid in Congo red-and thioflavin S-positive plaques [100]. This new generation of plaques typical for late-onset $\mathrm{AD}$ consists of fibrillar amyloid cores surrounded by several microglial cells, each with a unique amyloid pole with numerous cytoplasmic channels filled with bundles of amyloid fibers. The merger of these bundles of amyloid contributes to the growth of the size of the amyloid core. Leak of fibrillar amyloid at the core periphery results in exposure of surrounding dendrites, axons, and synapses to direct contact with amyloid, leading to degeneration of mitochondria and cytoskeleton and accumulation in swelling segments of neuronal processes and synapses of residues of neuron organelles, cytoskeleton, and paired helical filaments in neurons already affected by neurofibrillary degeneration [96]. Severe injury of neuronal processes and synapses in each fibrillar plaque parallel to an increase in the number of fibrillar plaques and fibrillar amyloid load in adult and aging DS subjects is associated with functional decline and dementia in the fifth and sixth decades of life of DS subjects analogous to the combination of fibrillar amyloidosis, neurofibrillary degeneration, neuronal loss, and dementia in LOAD. The presence of diffuse amyloid deposits without neuronal degeneration in the molecular layer in the cerebellar cortex, striatum, or presubiculum $[50,102]$ during the entire course of AD confirms mechanistic and functional separation of diffuse and fibrillar amyloid stages of AD pathology in DS subjects [40].

\section{Cerebral amyloid angiopathy}

The study by Head et al. [28] of cerebrovascular pathology including cerebral amyloid angiopathy (CAA), atherosclerosis, and arteriosclerosis revealed CAA in 87.1\% of DS subjects, in $72.2 \%$ in a SAD cohort, and $18.4 \%$ in a control cohort, and an increase of prevalence of severe CAA with age among DS subjects but not in SAD and the control group. In the examined DS cohort, amyloid angiopathy has been detected in all DS subjects 41-72 years of age in all four examined regions, including the EC, CA1, subiculum, and molecular layer in the cerebellar cortex. The study revealed that the number of amyloidpositive vessels reaches a top level in 61- to 72-year-old DS subjects. The increase in the numerical density of amyloid-positive vessels detected in each of four examined brain structures in 61- to 72-year-old DS subjects compared to 41- to 59-year-old DS subjects is consistent with the association between increasing CAA severity and age detected in amyloid precursor protein-overexpressing DS subjects [10, 28].

Growth of deposits of fibrillar $\beta$-amyloid in the capillary basal lamina results in perivascular amyloid hemistar formation covered by a mantle of microglial cells, death of endothelial cells, obliteration of affected capillary lumen, microbleeds, and local ischemic changes with neuronal degeneration and death [97, 98]. Amyloidosis of arterioles and arteries is mechanistically separate from capillary amyloidosis. Fibrillar amyloid deposition by smooth muscle cells in the wall of arterioles/arteries results in the degeneration and death of smooth muscle cells in the tunica media, the loss of mechanical strength of artery walls, and the increased risk of disruption of vascular wall and microbleeds [99]. Increase in amyloid angiopathy in all four examined regions in the sixth decade of life of DS subjects indicates that the progression of amyloid angiopathy contributes to regional ischemia, neuronal degeneration and loss, and possibly to functional deterioration. Cerebral amyloid angiopathy leading 
to vascular dysfunction with impaired vessel constriction and dilation, blood-brain barrier disruption, microhemorrhages, and more severe cerebral amyloid angiopathy in $\mathrm{DS} / \mathrm{AD}$ than SAD was reported by Head et al. [28]. The association between significant cerebral amyloid angiopathy with deposition of $A \beta$ in the wall of small and medium-size arteries in the cerebral cortex and vascular wall damage with chronic microbleeds [29] or large intracerebral hemorrhages [17] supports the concept of cerebrovascular pathology contributing significantly to AD neuropathology and dementia [34, 81].

Role of overexpressed minibrain kinase DYRK1A in trisomic DS subjects in synchrony of neurofibrillary degeneration, $\beta$-amyloidosis, and functional decline/dementia

Similarities of trajectories of Braak and Thal staging of the onset and progression of both neurofibrillary degeneration and $\beta$-amyloidosis and the corresponding onset and progression of dementia in the DS cohort suggest the contribution of common DS-associated underlying molecular mechanisms.

Early onset of $\beta$-amyloidosis in DS is considered a result of overexpression of $\beta$-amyloid precursor protein (APP), which is encoded by a gene proximal to the DS critical region of chromosome 21 . Novel studies revealed a link between overexpression of Dyrk1A gene located in the DS critical region of chromosome 21 and neurofibrillary degeneration and $\beta$-amyloidosis [21, 37, 47, 92]. Dyrk1A (dual-specificity tyrosine-phosphorylated and regulated kinase 1A) phosphorylates tau protein at Thr212 and several other sites and promotes further phosphorylation by GSK- $3 \beta$ and increases the level of abnormally hyperphosphorylated tau. Overexpression of DYRK1A [18] is associated with hyperphosphorylation of these sites in DS, inhibition of tau's biological activity, gain of toxic activity leading to sequestration of normal tau and other microtubule-associated proteins, resulting in neuronal degeneration [21] and promotion of tau self-aggregation into NFTs [47, 90, 91]. Moreover, Dyrk1A phosphorylates APP at Thr668, resulting in elevation of the level of phosphorylated APP detected in DS brains [74]. Phosphorylation of APP enhances increasing levels of $A \beta 40 / 42$ by precursor amyloidogenic cleavage, toxic $A \beta$ oligomer formation, deposition of fibrillar amyloid in plaques, and degeneration of axons, dendrites, and synapses within the fibrillar plaque perimeter. Overproduction of $A \beta$ may up-regulate DYRK1A expression and enhance the contribution of overexpressed DYRK1A to both neurofibrillary degeneration and associated neuronal loss [92] and to the age-associated increase of amyloid load detected in this study.

This study reveals that the range of developmental neuronal deficits contributing to the intellectual deficits of subjects with DS is comparable to the AD-associated neuronal loss contributing to dementia in adult DS subjects. The reduced size of the brain, decrease in neuronal density in the brain of individuals with DS $[13,75,106]$, and decreased cell proliferation in the hippocampal dentate gyrus and in the neocortical germinal matrix of fetuses with DS [11, 24] are an effect of decrease in the neurogenesis associated with overexpression of DYRK1A in progenitor cells. DYRK1A is required for the proliferation of distinct neuronal cell types during postembryonic neurogenesis. However, overexpressed DYRK1A may contribute to depletion of the pool of proliferating progenitor cells and may induce premature cell cycle arrest of neurogenic progenitors, leading to a decrease in the number of neurons generated by each progenitor cell [83].

Studies of the contribution of DYRK1A to abnormal brain development and neurogenesis and results of the estimation of developmental neuronal deficits in this study indicate that therapeutic reduction of overexpressed DYRK1A in DS subjects during their development may reduce developmental abnormalities, including defective neurogenesis, which results in a reduced number of neurons and intellectual deficits. The above-cited studies of the contribution of overexpressed DYRK1A to brain $\beta$-amyloidosis, neurofibrillary degeneration, neuronal loss, and dementia indicate that therapeutic inhibition of excessive activity of overexpressed DYRK1A in DS individuals may disrupt both pathological pathways and arrest/slow down neurodegeneration, neuronal loss, and related functional decline [92].

\section{Study limitations and conclusions}

The small number of examined DS individuals in the 26-41 and 41-49 years of age groups (4 in each group) limits this part of study to a descriptive approach at this point. Further investigation would require greater tissue acquisition.

The commonly known discrepancy between the reported ubiquity of $\mathrm{AD}$ neuropathology in the fourth decade of life of DS subjects and the absence of dementia even at the age of 70 years $[27,77,109,110]$ is partially associated with the challenges of cognitive assessment of DS subjects [5, 51]. The review by Ballard et al. [5] demonstrating that $55 \%$ of individuals with DS develop dementia between 40 and 49 years of age and that the percentage of affected people grows to $77 \%$ in 60 - to 69-year-old subjects discloses the gap between staging of dementia and the ubiquitous brain AD pathology detected postmortem in DS cohorts. The other limitations of clinicopathological correlations are the difficulties of diagnosis and staging of dementia in DS subjects with a broad spectrum of developmental intellectual 
deficits and the high prevalence of comorbid conditions such as epilepsy [55, 67], hypothyroidism, hypertension, diabetes mellitus, and hyperlipidemia [54], which may contribute to functional decline and onset/aggravation of dementia [77]. These interindividual differences may expand the gap between clinical staging of dementia and postmortem staging of pathology. The difficulties with detection of correlations between clinical staging of dementia in $\mathrm{DS}$ and postmortem staging of AD pathology also arise because of the limited accessibility of postmortem material and the common gaps in clinical follow-up for brains donated for research, leading to assessment of dementia based on review of available, not necessarily standardized, medical records, as was applied in this and other studies [28].

Despite the limitations of clinical assessments, this study provides evidence of strong correlations between age and stage of dementia and unbiased measures of the progression of AD pathology in individuals with DS in the fourth, fifth, and sixth decades of life. The study revealed a similar magnitude of developmental deficits of neurons due to trisomy 21 contributing to intellectual deficits and $\mathrm{AD}$-associated neuronal loss leading to dementia. This study demonstrates that age-based staging of pathology in the fourth, fifth, and sixth decades of life in EOAD in DS corresponds to FAST-based staging of pathology in LOAD as well as FAST-based functional decline classified as MCI/mild AD (FAST3-4), moderate and moderately severe AD (FAST 5-6), and severe AD (FAST 7) [94].

\section{Abbreviations \\ AD: Alzheimer's disease; DS: Down syndrome; AB: Amyloid- $\beta$ peptide; APP: A- $\beta$ precursor protein; EOAD: Early-onset AD; LOAD: Late-onset AD; FAST: Functional Assessment Staging; MCl: Mild cognitive impairment; EC: Entorhi- nal cortex; ECII: Second layer of the entorhinal cortex; CA: Cornu Ammonis; MBC: Magnocellular basal complex; MRI: Magnetic resonance imaging; NFTs: Neurofibrillary tangles.}

\section{Supplementary Information}

The online version contains supplementary material available at https://doi. org/10.1186/s40478-021-01300-9.

Additional file 1. Stereological parameters and procedures applied for examination of DS brains.

\section{Acknowledgements}

Brain tissue of DS and control subjects was provided by the New York State Brain and Tissue Bank for Developmental Disabilities and Aging at the New York State Institute for Basic Research in Developmental Disabilities, the Brain and Tissue Bank for Developmental Disorders of the National Institute of Child Health and Human Development at the University of Maryland, and the Alzheimer's Disease Research Center at the New York University Grossman School of Medicine. The authors thank Mrs. Maureen Marlow for manuscript editing, Dr. Wojciech Kaczmarski for help in APOE genotyping and results interpretation, Mrs. Jadwiga Wegiel and Mrs. En Wu Zheng for histology and immunocytochemistry.

\section{Authors' contributions}

Jerzy W, TW, and ML designed the project, coordinated the efforts of several groups' processing of tissue and performance of neuropathological and morphometric studies, and drafted the manuscript. MF participated in the design of the study and performed statistical analysis. TW, TWB, and IK provided neuropathological evaluation and Braak and Braak as well as Thal staging. IK, KN, Jarek W, and SYM performed morphometric studies, created the database for statistical analysis, and assisted in drafting of the manuscript. FL and TWB assisted in tissue and clinical records acquisition, and interpretation of clinicopathological correlations. WPS and NZ contributed to research design, interpretation of data and results, and drafting of the manuscript. All authors read and approved the final manuscript

\section{Funding}

The study was supported in part by funds from the New York State Office for People With Developmental Disabilities and grants from the NIH National Institute of Child Health and Human Development, R01 HD43960 (JW) and the National Institute of Aging (P30AG066512 and AG060882, TW, ML, JW).

\section{Availability of data and materials}

The datasets generated and analyzed in this study are available from the corresponding author on a reasonable request. A large portion of the data is presented in 10 Tables and 7 figures/graphs.

\section{Declarations}

Ethics approval and consent to participate

All procedures involving human tissues were performed in accordance with the World Medical Association Declaration of Helsinki. Experimental protocols were approved by IBR's Institutional Review Board. The study was performed by using coded and anonymized brain tissue samples obtained from the tissue banks listed in the Acknowledgements. The anonymized extracts of clinical records were obtained from the New York State Brain and Tissue Bank for Developmental Disabilities and Aging at the New York State Institute for Basic Research in Developmental Disabilities.

\section{Consent for publication}

Not applicable.

\section{Competing interests}

The authors declare that they have no competing interests.

\section{Author details}

${ }^{1}$ Department of Developmental Neurobiology, NYS Institute for Basic Research in Developmental Disabilities, 1050 Forest Hill Road, Staten Island, NY 10314, USA. ${ }^{2}$ New York State Institute for Basic Research in Developmental Disabilities (IBR), Staten Island, NY, USA. ${ }^{3}$ Institute of Psychiatry and Neurology, Warsaw, Poland. ${ }^{4}$ Department of Radiology, Weill Cornell Medicine, New York, NY, USA. ${ }^{5}$ Department of Neurology, Massachusetts General Hospital, Harvard Medical School, Boston, MA, USA. ${ }^{6}$ Department of Pediatrics, Irvine Medical Center, University of California, Irvine, CA, USA. ${ }^{7}$ Center for Cognitive Neurology, Departments of Neurology, Pathology and Psychiatry, NYU Grossman School of Medicine, New York, NY 10016, USA.

Received: 14 October 2021 Accepted: 2 December 2021

Published online: 04 January 2022

\section{References}

1. Amador-Ortiz C, Lin WL, Ahmed Z, Personett D, Davies P, Duara R et al (2007) TDP-43 immunoreactivity in hippocampal sclerosis and Alzheimer's disease. Ann Neurol 61:435-445. https://doi.org/10.1002/ana. 21154

2. Amaral DG, Insausti R (1990) Hippocampal formation. In: Paxinos G (ed) The human nervous system. Academic Press Inc, San Diego, CA, pp 711-755

3. Annus T, Wilson LR, Acosta-Cabronero J, Cardenas-Blanco A, Hong YT, Fryer TD et al (2017) The Down syndrome brain in the presence and 
absence of fibrillar $\beta$-amyloidosis. Neurobiol Aging 53:11-19. https:// doi.org/10.1016/j.neurobiolaging.2017.01.009

4. Arai T, Mackenzie IR, Hasegawa M, Nonaka T, Niizato K, Tsuchiya K et al (2009) Phosphorylated TDP-43 in Alzheimer's disease and dementia with Lewy bodies. Acta Neuropathol 117:125-136. https://doi.org/10. 1007/s00401-008-0480-1

5. Ballard C, Mobley W, Hardy J, Williams G, Corbett A (2016) Dementia in Down's syndrome. Lancet Neurol 15:622-636. https://doi.org/10.1016/ S1474-4422(16)00063-6

6. Boyle PA, Wang T, Yu L, Wilson RS, Dawe R, Arfanakis K, et al (2021) To what degree is late life cognitive decline driven by age-related neuropathologies? Brain. https://doi.org/10.1093/brain/awab092

7. Braak H, Braak E (1991) Neuropathological staging of Alzheimer-related changes. Acta Neuropathol 82:239-259. https://doi.org/10.1007/BF003 08809

8. Brookmeyer R, Corrada MM, Curriero RC et al (2002) (2002) Survival following a diagnosis of Alzheimer's disease. Arch Neurol 59:1764-1767. https://doi.org/10.1001/archneur.59.11.1764

9. Buciuc M, Tosakulwong N, Machulda MM, Whitwell JL, Weigand SD, Murray ME et al (2021) TAR DNA-Binding Protein 43 is associated with rate of memory, functional and global cognitive decline in the decade prior to death. J Alzheimers Dis 80:683-693. https://doi.org/10.3233/ JAD-201166

10. Burger PC, Vogel FS (1973) The development of pathological changes of Alzheimer's disease and senile dementia in patients with Down's syndrome. Am J Pathol 73:457-476. PMCID: PMC1 904076

11. Carmona-Iragui M, Videla L, Lleo A, Fortea J (2019) Down syndrome, Alzheimer disease, and cerebral amyloid angiopathy. The complex triangle of brain amyloidosis. Dev Neurobiol 79:716-737. https://doi. org/10.1002/dneu.22709

12. Contestabile A, Fila T, Ceccarelli C, Bonasini P, Bonapace L, Santini D et al (2007) Cell cycle alteration and decreased cell proliferation in the hippocampal dentate gyrus and in the neocortical germinal matrix of fetuses with Down syndrome and in Ts65Dn mice. Hippocampus 17:665-678. https://doi.org/10.1002/hipo.20308

13. Coppus AM, Evenhuis HM, Verberne GJ, Visser FE, Arias-Vasquez A, Sayed-Tabatabaci FA et al (2008) The impact of apolipoprotein E on dementia in persons with Down's syndrome. Neurobiol Aging 29:828-835. https://doi.org/10.1016/j.neurobiolaging.2006.12.013

14. Coyle JT, Oster-Granite ML, Gearhart JD (1986) The neurobiologic consequences of Down syndrome. Brain Res Bull 16:773-787. https:// doi.org/10.1016/0361-9230(86)90074-2

15. Davidson YS, Raby S, Foulds PG, Robinson A, Thompson JC, Sikkink S et al (2011) TDP-43 pathological changes in early onset familial and sporadic Alzheimer's disease, late onset Alzheimer's disease and Down's syndrome: association with age, hippocampal sclerosis and clinical phenotype. Acta Neuropathol 122:703-713. https://doi.org/10.1007/ s00401-011-0879-y

16. Davidson YS, Robinson A, Prasher VP, Mann DMA (2018) The age of onset and evolution of Braak tangle stage and Thal amyloid pathology of Alzheimer's disease in individuals with Down syndrome. Acta Neuropathol Comm 6:56. https://doi.org/10.1186/s40478-018-0559-4

17. de la Monte SM, Headley-White T (1990) Small cerebral hemispheres in adults with Down syndrome: contributions of developmental arrest and lesions of Alzheimer's disease. J Neuropath Exp Neurol 49:509-520. https://doi.org/10.1097/00005072-199009000-00006

18. Donahue JE, Khurana JS, Adelman LS (1998) Intracerebral hemorrhage in two patients with Down syndrome and cerebral amyloid angiopathy. Acta Neuropathol 95:213-216. https://doi.org/10.1007/s004010050789

19. Dowjat WK, Adayev T, Kuchna I, Nowicki K, Palminiello S, Hwang Y-W et al (2007) Trisomy driven overexpression of DYRK1A kinase in the brain of subjects with Down syndrome. Neurosci Lett 413:77-81. https://doi.org/10.1016/j.neulet.2006.11.026

20. Duvernoy HM (1988) The human hippocampus. An atlas of applied anatomy. J.F. Bergmann-Verlag München, Munich, Germany

21. Fearnley JM, Lees AJ (1993) Pathology of Parkinson's disease. In: Calne DB (eds) Neurodegenerative diseases. Saunders Company, Philadelphia, PA, p. 545-554

22. Gong C-X, Liu F, lqbal K (2006) Dysregulation of protein phosphorylation /dephosphorylation in Alzheimer's disease: a therapeutic target.
J Biomed Biotech Article ID 31825:1-11. https://doi.org/10.1155/JBB/ 2006/31825

23. Gould W (2019) Stata Statistical Software. Release 16. College Station. TX: Stata Corp LLC

24. Grundke -labal I, Iqbal K, Tung YC, Quinlan M, Wisniewski H, Binder $L$ (1986) Abnormal phosphorylation of the microtubule associated protein $\mathrm{\tau}(\mathrm{tau})$ in Alzheimer cytoskeletal pathology. Proc Natl Acad Sci USA 83:4913-4917. https://doi.org/10.1073/pnas.83.13.4913

25. Guidi S, Bonasoni P, Ceccarelli C, Santini D, Gualtieri F, Ciani E et al (2008) Neurogenesis impairment and increased cell death reduce total neuron number in the hippocampal region of fetuses with Down syndrome. Brain Pathol 18:180-197. https://doi.org/10.1111/j.1750-3639.2007. 00113.x

26. Gundersen HJG, Jensen EBV, Kieu K, Nielsen J (1999) The efficiency of systematic sampling-reconsidered. J Micr 193:199-211. https://doi. org/10.1046/j.1365-2818.1999.00457.x

27. Hartley D, Blumenthal T, Carillo M, DiPaolo G, Esralew L, Gardiner K et al (2015) Down syndrome and Alzheimer's disease: common pathways, common goals. Alzheimers Dement 11:700-709. https://doi.org/10. 1016/j.jalz.2014.10.007

28. Head E, Lott IT, Patterson D, Doran E, Haier RJ (2007) Possible compensatory events in adult Down syndrome brain prior to the development of Alzheimer disease neuropathology: targets for nonpharmacological intervention. J Alzheimers Disease 11:61-76. https://doi.org/10.3233/ jad-2007-11110

29. Head E, Phelan MJ, Doran E, Kim RC, Poon WW, Schmitt FA et al (2017) Cerebrovascular pathology in Down syndrome and Alzheimer disease. Acta Neuropathol Comm 5:93. https://doi.org/10.1186/ s40478-017-0499-4

30. Helman AM, Siever M, McCarty KL, Lott IT, Doran E, Abner EL et al (2018) Microbleeds and cerebral amyloid angiopathy in the brains of people with Down syndrome with Alzheimer's disease. J Alzheimers Dis 67:103-112. https://doi.org/10.3233/JAD-180589

31. Hof PR, Bouras C, Perl DP, Sparks DL, Mehta N, Morrison JH (1995) Agerelated distribution of neuropathologic changes in the cerebral cortex of patients with Down's syndrome. Quantitative regional analysis and comparison with Alzheimer's disease. Arch Neurol 52:379-391. https:// doi.org/10.1001/archneur.1995.00540280065020

32. Jacobs PA, Baikie AG, Court Brown WM, Strong JA (1959) The somatic chromosomes in mongolism. Lancet 7075:710. https://doi.org/10.1016/ s0140-6736(59)91892-6

33. Josephs KA, Whitwell JL, Weigand SD, Murray ME, Tosakulwong N, Liesinger AM et al (2014) TDP-43 is a key player in the clinical features associated with Alzheimer's disease. Acta Neuropathol 127:811-824. https://doi.org/10.1007/s00401-014-1269-z

34. Josephs KA, Murray ME, Whitwell JL, Tosakulwong N, Weigand SD, Petrucelli L et al (2016) Updated TDP-43 in Alzheimer's disease staging scheme. Acta Neuropathol 131:571-585. https://doi.org/10.1007/ s00401-016-1537-1

35. Kalaria RN (2016) Neuropathological diagnosis of vascular cognitive impairment and vascular dementia with implications for Alzheimer's disease. Acta Neuropathol 131:659-685. https://doi.org/10.1007/ s00401-016-1571-z

36. Kapasi A, DeCarli C, Schneider J (2017) Impact of multiple pathologies on threshold for clinically overt dementia. Acta Neuropathol 134:171-186. https://doi.org/10.1007/s00401-017-1717-7

37. Kim KS, Miller DL, Sapienza VJ, Chen CMJ, Bai C, Grundke-lqbal I et al (1988) Production and characterization of monoclonal antibodies reactive to synthetic cerebrovascular amyloid peptide. Neurosci Res Commun 2:121-130

38. Kimura R, Kamino K, Yamamoto M, Nuripa A, Kida T, Kazui H et al (2007) The DYRK1A gene, encoded in chromosome 21 Down syndrome critical region, bridges between $\beta$-amyloid production and tau phosphorylation in Alzheimer disease. Hum Mol Genetics 16:15-23. https://doi.org/ 10.1093/hmg/ddl437

39. King A, Sweeny F, Bodi I, Troakes C, Maekawa S, Al-Sarraj S (2010) Abnormal TDP-43 expression is identified in the neocortex in cases of dementia pugilistica, but is mainly confined to the limbic system in high and moderate stages of Alzheimer's disease. Neuropathology 30:408-419. https://doi.org/10.1111/j.1440-1789.2009.01085.x 
40. Lai F, Williams RS (1989) A prospective study of Alzheimer disease in Down syndrome. Arch Neurol 46:849-853. https://doi.org/10.1001/ archneur.1989.00520440031017

41. Lalowski M, Golabek A, Lemere CA, Selkoe D, Wisniewski HM, Beavis RC et al (1996) The "nonamyloidogenic" p3 fragment (amyloid $\beta 17-42$ ) is a major constituent of Down's syndrome cerebellar preamyloid. J Biol Chem 271:33623-33631. https://doi.org/10.1074/jbc.271.52.33623

42. Larsen KB, Laursen H, Graem N, Samuelsen GB, Bogdanovic N, Pakkenberg B (2008) Reduced cell number in the neocortical part of the human fetal brain in Down syndrome. Ann Anat 190:421-427. https:// doi.org/10.1016/j.aanat.2008.05.007

43. Lejeune J, Le M (1959) Premiere example d'aberration autosomique humaine. Ann Genet 1:41-49

44. Leverenz JB, Raskind MA (1998) Early amyloid deposition in the medial temporal lobe of young Down syndrome patients: a regional quantitative analysis. Exp Neurol 150:296-304. https://doi.org/10.1006/exnr. 1997.6777

45. Lippa CF, Fujiwara H, Mann DMA, Giasson B, Baba M, Schmidt ML et a (1998) Lewy bodies contain altered alpha-synuclein in brains of many familial Alzheimer's disease patients with mutations in presenilin and amyloid precursor protein genes. Am J Pathol 153:1365-1370. https:// doi.org/10.1016/s0002-9440(10)65722-7

46. Lippa CF, Schmidt ML, Lee VMY, Trojanowski JQ (1999) Antibodies to a-synuclein detect Lewy bodies in Down's syndrome brains with Alzheimer's disease. Ann Neurol 45:353-357. https://doi.org/10.1002/ 1531-8249(199903)45:3\%3c353::aid-ana11\%3e3.0.co;2-4

47. Lippa CF, Rosso AL, Stutzbach LD, Neumann M, Lee VM-Y, Trojanowsk JQ (2009) Transactive response DNA-binding protein 43 burden in familial Alzheimer disease and Down syndrome. Arch Neurol 66:14831488. https://doi.org/10.1001/archneurol.2009.277

48. Liu F, Liang Z, Wegiel J, Hwang Y-W, lqbal K, Grundke-lqbal I et al (2008) Overexpression of Dyrk1A contributes to neurofibrillary degeneration in Down syndrome. FASEB J 22:3224-3233. https://doi.org/10.1096/fi. 07-104539

49. Mann DM, Yates PO, Marcyniuk B, Ravindra CR (1987) Loss of neurons from cortical and subcortical areas in Down's syndrome patients at middle age. Quantitative comparisons with younger Down's patients and patients with Alzheimer's disease. J Neurol Sci 80:79-89. https:// doi.org/10.1016/0022-510x(87)90223-1

50. Mann DMA, Esiri MM (1989) The pattern of acquisition of plaques and tangles in the brains of patients under 50 years of age with Down's syndrome. J Neurol Sci 89:169-179. https://doi.org/10.1016/0022-510x(89) 90019-1

51. Mann DMA, Iwatsubo T (1996) Diffuse plaques in the cerebellum and corpus striatum in Down's syndrome contain amyloid beta protein (A beta) only in the form of A beta 42(43). Neurodegeneration 5:115-120. https://doi.org/10.1006/neur.1996.0017

52. Margallo-Lana ML, Moore PB, Kay DW, Perry RH, Reid BE, Berney TP et al (2007) Fifteen-year follow-up of 92 hospitalized adults with Down's syndrome: incidence of cognitive decline, its relationship to age and neuropathology. J Intellct Disabil Res 51:463-477. https://doi.org/10. 1111/j.1365-2788.2006.00902.x

53. McCarron M, Mc Callion P, Reilly E, Mulryan N (2014) A prospective 14-years longitudinal follow-up of dementia in persons with Down syndrome. J Intellect Disabil Res 58:61-70. https://doi.org/10.1111/jir. 12074

54. McCarron M et al (2017) A prospective 20-year longitudinal follow-up of dementia in persons with Down syndrome. J Intelect Disabil Res 61:843-852. https://doi.org/10.1111/jir.12390]

55. McDonald RJ, Craig LA, Hong NS (2010) The etiology of age-related dementia is more complicated than we think. Behav Brain Res 214:3-11. https://doi.org/10.1016/j.bbr.2010.05.005

56. Menendez M (2005) Down syndrome, Alzheimer's disease and seizures. Brain Dev 27:246-252. https://doi.org/10.1016/j.braindev.2004.07.008

57. Mesulam MM, Mufson EJ, Levey Al, Wainer BH (1983) Cholinergic innervation of cortex by basal forebrain: cytochemistry and cortical connections of the septal area, diagonal band nuclei, nucleus basalis (substantia innominata) and hypothalamus in the rhesus monkey. J Comp Neurol 214:170-197. https://doi.org/10.1002/cne.902140206

58. Moreno DG, Utagawa EC, Arva NC, Schafernak KT, Mufson EJ, Perez SE (2022) Postnatal cytoarchitecture and neurochemical hippocampal dysfunction in Down syndrome. J Clin Med 10:3414. https://doi.org/10. $3390 / \mathrm{jcm} / 10153414$

59. Nelson PT, Abner EL, Patel E, Anderson SA, Wilcock DM, Kryscio RJ et al (2018) The amygdala as a locus of pathologic misfolding in neurodegenerative diseases. J Neuropathol Exp Neurol 77:2-20. https:// doi.org/10.1093/jnen/nlx099

60. Nelson PT, Dickson DW, Trojanowski JQ, Jack CR, Boyle PA, Arfanakis $K$ et al (2019) Limbic-predominant age-related TDP-43 encephalopathy (LATE): consensus working group report. Brain 142:1503-1527. https://doi.org/10.1093/brain/awz099

61. Patkee PA, Baburamani AA, Kyriakopoulou V, Davidson A, Avini E, Dimitrova R et al (2020) Early alterations in cortical and cerebellar regional brain growth in Down Syndrome an: in vivo fetal and neonatal MRI assessment. Neurolmage Clinical 25:102139 https://doi.org/ 10.1016/j.nicl.2019.102139

62. Perez SE, Miguel JC, He B, Malek-Ahmadi M, Abrahamson EE, Ikonomovic MD et al (2019) Frontal cortex and striatal cellular and molecular pathobiology in individuals with Down syndrome with and without dementia. Acta Neuropathol 137:413-436. https://doi. org/10.10007/s00401-019-01965-6

63. Pinter JD, Eliez S, Schmitt JE, Capone GT, Reiss AL (2001) Neuroanatomy of Down's syndrome: a high-resolution MRI study. Am J Psychiatry 158:1659-1665. https://doi.org/10.1176/appi.ajp.158.10. 1659

64. Pinter JD, Brown WE, Eliez S, Schmitt JE, Capone GT, Reiss AL (2001) Amygdala and hippocampal volumes in children with Down syndrome: a high-resolution MRI study. Neurology 56:972-974. https:// doi.org/10.1212/wnl.56.7.972

65. Prasher VP, Filer A (1995) Behavioural disturbance in people with Down's syndrome and dementia. J Intellect Disabil Res 39:432-436. https://doi.org/10.1111/j.1365-2788.1995.tb00547.x

66. Prasher VP, Schupf N, Sajitah SG, Zigman WB, Rees SD, Patel A et al (2008) Significant effect of APOE epsilon 4 genotype on the risk of dementia in Alzheimer's disease and mortality in persons with Down syndrome. Int J Geriatr Psychiatry 23:1134-1140. https://doi.org/10. 1002/gps.2039

67. Presson AP, Partyka G, Jensen KM, Devine OJ, Rasmussen SA, McCabe LL et al (2013) Current estimate of Down syndrome population prevalence in the United States. J Pediatr 163:1163-1168. https://doi. org/10.1016/j.jpeds.2013.06.013

68. Puri BK, Ho KW, Singh I (2001) Age of seizure onset in adults with Down's syndrome. Int J Clin Pract 55:442-444 (PMID: 11594252)

69. Raghaven R, Khin-Nu C, Brown A, Irving D, Ince PG, Day K, Tyrer SP, Perry RH (1993) Detection of Lewy bodies in Trisomy 21 (Down syndrome). Canad J Neurol Sci 20:48-51. https://doi.org/10.1017/s0317 167100047405

70. Reisberg B (1988) Functional assessment staging (FAST). Psychopharmacol Bull 24:653-659 (PMID: 3249767)

71. Ropper AH, Williams RS (1980) Relationship between plaques and tangles and dementia in Down's syndrome. Neurology 30:639-644. https://doi.org/10.1212/wnl.30.6.639

72. Rosene DL (1987) van Hoesen GW (1987) The hippocampal formation of the primate brain: A review of some comparative aspects of cytoarchitecture and connections. In: Jones EG, Peters A (eds) Cerebral Cortex, vol 6. Plenum, New York, NY, pp 345-456

73. Ross MH, Galaburda AM, Kemper TL (1984) Down's syndrome: is there a decreased population of neurons? Neurology 34:909-916. https:// doi.org/10.1212/wnl.34.7.909

74. Royston MC, Mann D, Pickering-Brown S, Owen F, Perry R, Raghavan R et al (1994) Apolipoprotein E epsilon 2 allele promotes longevity and protects patients with Down's syndrome from dementia. NeuroReport 5:2583-2585. https://doi.org/10.1097/00001756-19941 2000-00044

75. Ryoo SR, Cho HJ, Lee HW et al (2008) Dual specificity tyrosine (Y)-phosphorylation regulated kinase $1 \mathrm{~A}$-mediated phosphorylation of amyloid precursor protein: evidence for a functional link between Down syndrome and Alzheimer's disease. J Neurochem 104:1333-1344. https:// doi.org/10.1111/j.1471-4159.2007.05075.x

76. Schmidt-Sidor B, Wisniewski KE, Shepard TH, Sersen EA (1990) Brain growth in Down syndrome subjects 15 to 22 weeks of gestational age and birth to 60 months. Clin Neuropathol 9:181-190 (PMID: 2146054) 
77. Schupf N, Kapell D, Lee HJ, Zigman WB, Canto B, Tycko B et al (1996) Onset of dementia is associated with apolipoprotein E epsilon4 in Down's syndrome. Ann Neurol 40:799-801. https://doi.org/10.1002/ana. 410400518

78. Schupf N (2002) Genetic and host factors for dementia and Down's syndrome. British J Psychiatry 180:405-410. https://doi.org/10.1192/bjp. 180.5.405

79. Shiohama T, Levman J, Baumer N, Takahashi E (2019) Structural Rl-based brain morphology study in infants and toddlers with Down syndrome; the effect of comorbidities. Pediatr Neurol 100:67-73. https://doi.org/ 10.1016/j.pediatrneurol.2019.03.015

80. Snyder HM, Bain LJ, Brickman AM, Carillo MC, Esbensen AJ, Esponosa JM et al (2020) Further understanding the connection between Alzheimer's disease and Down syndrome. Alzheimers Dement 16:1065-1077. https://doi.org/10.1002/alz.12112

81. Startin CM, D'Souza H, Ball G, Hamburg S, Hithersay R, Hughes KMO et al (2020) Health comorbidities and cognitive abilities across the lifespan in Down syndrome. J Neurodevel Dis 12:3-13. https://doi.org/ 10.1186/s11689-019-9306-9

82. Strozyk D, Dickson DW, Lipton RB, Katz M, Derby CA, Lee S et al (2010) Contribution of vascular pathology to the clinical expression of dementia. Neurobiol Aging 31:1710-1720. https://doi.org/10.1016/..neurobiola ging.2008.09.011

83. Tarui T, Im K, Madan N, Madankumar R, Skotko BG, Schwartz A et al (2020) Quantitative MRI analyses of regional brain growth in living fetuses with Down Syndrome. Cereb Cortex 30:382-390. https://doi. org/10.1093/cercor/bhz094

84. Tejedor FJ, Hämmerle B (2011) MNB/DYRK1A as a multiple regulator of neuronal development. FEBS J 278:223-235. https://doi.org/10.1111/j. $1742-4658.2010 .07954 . x$

85. Thal DR, Rüb U, Orantes M, Braak H (2002) Phases of Aß-deposition in the human brain and its relevance for the development of AD. Neurology 58:1791-1800. https://doi.org/10.1212/wnl.58.12.1791

86. Tomé SO, Vanderberghe R, Ospitalieri S, Van Schoor E, Touseyn T, Otto M et al (2020) Distinct molecular patterns of TDP-43 pathology in Alzheimer's disease: relationship with clinical phenotypes. Acta Neuropathol Commun 8:61. https://doi.org/10.1186/s40478-020-00934-5

87. Tomé SO, Gomes LA, Li X, Vanderberghe R, Tousseyn T, Thal DR (2021) TDP-43 interacts with pathological t protein in Alzheimer's disease. Acta Neuropathol 141:795-799. https://doi.org/10.1007/s00401-021-02295-2

88. Uryu K, Nakashima-Yasuda H, Forman MS, Kwong LK, Clark CM, Grossman M et al (2008) Concomitant TAR-DNA-binding protein 43 pathologies present in Alzheimer disease and corticobasal degeneration but not in other tauopathies. J Neuropathol Exp Neurol 67:555-564. https:// doi.org/10.1097/NEN.0b013e31817713b5

89. Vogels OJ, Broere CA, ter Laak HJ, ten Donkelaar HJ, Nieuwenhuys R, Shulte BP et al (1990) Cell loss and shrinkage in the nucleus basalis Meynerti complex in Alzheimer's disease. Neurobiol Aging 11:3-13. https://doi.org/10.1016/0197-4580(90)90056-6

90. Wang HY, Wang IF, Bose J, Shen CK (2004) Structural diversity and functional implications of the eukaryotic TDP gene family. Genomics 83:130-139. https://doi.org/10.1016/s0888-7543(03)00214-3

91. Wegiel J, Dowjat K, Kaczmarski W, Kuchna I, Nowicki K, Frackowiak J et al (2008) The role of overexpressed DYRK1A protein in the early onset of neurofibrillary degeneration in Down syndrome. Acta Neuropathol 116:391-407. https://doi.org/10.1007/s00401-008-0419-6

92. Wegiel J, Kaczmarski W, Barua M, Kuchna I, Nowicki K, Wang K-C et al (2010) Link between DYRK1A overexpression and several-fold enhancement of neurofibrillary degeneration with 3-repeat tau protein in Down syndrome. J Neuropathol Exp Neurol 70:36-50. https://doi.org/10.1097/ NEN.0b013e318202bfa1

93. Wegiel J, Gong C-X, Hwang Y-W (2011) The role of DYRK1A in neurodegenerative diseases. FEBS J 278:236-245. https://doi.org/10.1111/j. 1742-4658.2010.07955.x

94. Wegiel J, Flory M, Kuchna I, Nowicki K, Ma SY, JI W et al (2017) Multiregional age-associated reduction of brain neuronal reserve without association with neurofibrillary degeneration or $\beta$-amyloidosis. J Neuropathol Exp Neurol 76:439-457. https://doi.org/10.1093/jnen/n|x027

95. Wegiel J, Flory M, Kuchna I, Nowicki K, Ma SY, Wegiel J et al (2021) Clinicopathological staging of dynamics of neurodegeneration and neuronal loss in Alzheimer disease. J Neuropathol Exp Neurol 80:21-44. https://doi.org/10.1093/jnen/nlaa140

96. West MJ, Gundersen HJ (1990) Unbiased stereological estimation of the number of neurons in the human hippocampus. J Comp Neurol 296:122. https://doi.org/10.1002/cne.902960102

97. Wisniewski HM, Wegiel J, Wang KC, Kujawa M, Lach B (1989) Ultrastructural studies of the cells forming amyloid fibers in classical plaques. Can J Neurol Sci 16:535-542. https://doi.org/10.1017/s0317167100029887

98. Wisniewski HM, Wegiel J, Wang KC, Lach B (1992) Ultrastructural studies of the cells forming amyloid in the cortical vessel wall in Alzheimer's disease. Acta Neuropathol 84:117-127. https://doi.org/10.1007/BF003 11383

99. Wisniewski HM, Wegiel J (1993) Migration of perivascular cells into the neuropil and their involvement in $\beta$-amyloid plaque formation. Acta Neuropathol 85:586-595. https://doi.org/10.1007/BF00334667

100. Wisniewski HM, Wegiel J (1994) $\beta$-amyloid formation by myocytes of leptomeningeal vessels. Acta Neuropathol 87:233-241. https://doi.org/ 10.1007/BF00296738

101. Wisniewski HM, Wegiel J, Popovitch ER (1994) Age-associated development of diffuse and thioflavin-S-positive plaques in Down syndrome. Dev Brain Dysfunction 7:330-339

102. Wisniewski HM, Wegiel J (1995) The neuropathology of Alzheimer's disease. Neuroimaging Clin N Am 5:45-57 (PMID: 7743084)

103. Wisniewski HM, Sadowski M, Jakubowska-Sadowska K, Tarnawski M, Wegiel J (1998) Diffuse, lake I-like amyloid- $\beta$ deposits in the parvopyramidal layer of the presubiculum in Alzheimer's disease. J Neuropath Exp Neurol 57:674-683. https://doi.org/10.1097/00005072-19980 7000-00004

104. Wisniewski KE, Laure-Kamionowska M, Wisniewski HM (1984) Evidence of arrest of neurogenesis and synaptogenesis in brains of patients with Down's syndrome. N Engl J Med 311:1187-1188. https://doi.org/10. 1056/NEJM198411013111818

105. Wisniewski KE, Wisniewski H, Wen G (1985) Occurrence of neuropathological changes and dementia of Alzheimer's disease in Down syndrome. Ann Neurol 17:278-282. https://doi.org/10.1002/ana.41017 0310

106. Wisniewski KE, Dalton AJ, McLachlan C, Wen GY, Wisniewski HM et al (1985) Alzheimer disease in Down's syndrome; clinicopathological studies. Neurology 35:957-961. https://doi.org/10.1212/wnl.35.7.957

107. Wisniewski KE (1990) Down syndrome children often have brain with maturation delay, retardation of growth, and cortical dysgenesis. Am J Med Genet 7:274-281. https://doi.org/10.1002/ajmg.1320370755

108. Yang Q, Rasmussen SA, Friedman JM (2002) Mortality associated with Down's syndrome in the USA from 1983-1997; a population-based study. Lancet 359:1019-1025. https://doi.org/10.1016/s0140-6736(02) 08092-3

109. Zigman WB, Schupf N, Sersen E, Silverman W (1996) Prevalence of dementia in adults with and without Down syndrome. Am J Ment Ret 100:403-412 ([PubMed : 8718994])

110. Zigman WB, Lott IT (2007) Alzheimer's disease in Down syndrome: neurobiology and risk. Ment Retard Dev Disabil Res Rev 13:237-246. https://doi.org/10.1002/mrdd.20163

111. Zigman WB, Devenny DA, Krinsky-McHale SJ, Jenkins EC, Urv TK, Wegiel $J$ et al (2008) Alzheimer's disease in adults with Down syndrome. Int Rev Res Mental Retard 36:103-145. https://doi.org/10.1016/S0074-7750(08) 00004-9

\section{Publisher's Note}

Springer Nature remains neutral with regard to jurisdictional claims in published maps and institutional affiliations. 